Research Article

\title{
Seismic Study of Skew Bridge Supported on Laminated-Rubber Bearings
}

\author{
Xueshan Liu, ${ }^{1}$ Wei Guo $\mathbb{D}^{2}{ }^{2}$ Jianzhong $\mathrm{Li}^{1}$, and Hua Zhang ${ }^{1}$ \\ ${ }^{1}$ State Key Lab for Disaster Reduction in Civil Engineering, Tongji University, Shanghai 200092, China \\ ${ }^{2}$ T.Y.Lin International Engineering Consulting (China) Co., Ltd., Chongqing 401120, China
}

Correspondence should be addressed to Wei Guo; guowei@tylin.com.cn

Received 25 May 2020; Revised 31 October 2020; Accepted 4 November 2020; Published 19 November 2020

Academic Editor: Daniele Baraldi

Copyright (c) 2020 Xueshan Liu et al. This is an open access article distributed under the Creative Commons Attribution License, which permits unrestricted use, distribution, and reproduction in any medium, provided the original work is properly cited.

Skew bridges consisting of simply supported girders, continuous decks, and laminated-rubber bearings are widely used in western China; however, they are highly vulnerable to strong earthquakes. To investigate the seismic performance of skew bridges considering the sliding behavior of laminated-rubber bearings, the Duxiufeng Bridge located in Sichuan, China, was used as a prototype bridge. This bridge is a skew bridge that suffered seismic damage during the 2008 Wenchuan earthquake. The possible seismic response of this skew bridge under the Wenchuan earthquake was simulated, and the postearthquake repair methods were analyzed considering the effects of bearing types and cable restrainers. Parametric studies, using the finite element method, were also performed to investigate the effects of the skew angle and friction coefficient of the bearings on the seismic response of the skew bridge. The results indicate that pin-free bearings could effectively control the seismic displacement of the bridge, and the cable restrainers with an appropriate stiffness could significantly reduce the longitudinal residual displacements. The effect of skew angles is less significant on skew bridges with laminated-rubber bearings than on rigid-frame skew bridges because of the sliding between the girders and bearings. The residual displacements of the bearings were more sensitive to the variation in the friction coefficient between the laminated-rubber bearings and the girders compared to the maximum seismic displacements.

\section{Introduction}

Highway bridges, which are a crucial component of the transportation system, with a significant role in the rescue operations after earthquakes, have been extensively damaged to different degrees during major earthquakes in the past. The 1994 Northridge earthquake [1], 1995 Kobe earthquake [2], 1999 Chi-Chi earthquake [3], and 2008 Wenchuan earthquake [4] have demonstrated that highway bridges are highly vulnerable to earthquakes, and the collapse of a bridge might directly cut off the trunk roads, hindering the postearthquake rescue efforts to a large extent.

Laminated-rubber bearings featuring alternate layers of rubber and steel sheets, as shown in Figure 1, have been extensively used in small-to-medium-span highway bridges in China in recent decades, owing to their low cost and simple configurations. The bearings possess the capacity to sustain large vertical loads and accommodate the thermal movements of the superstructure with little or no maintenance requirements. Laminated-rubber bearings are used to support the superstructures, and the friction force is the only horizontal resisting force provided at the supports $[5,6]$. Once the seismic force exceeds the friction force, sliding leads to potentially large displacements. Large residual displacements may be generated, hindering the usage of the bridge after the earthquake. It is also possible that the bridge unseats and collapses as a result of large relative displacements between the superstructure and substructure (e.g., Miaoziping Bridge [7]). The seismic behavior of laminatedrubber bearings has been investigated by many researchers [8-10]. To obtain an analytical model of laminated-rubber bearings under earthquakes, Xiang and Li [10] performed an experiment on laminated-rubber bearings placed between two steel plates. An analytical model considering the sliding response of the bearings was developed and calibrated. The seismic behavior of the bearings before an evident sliding 


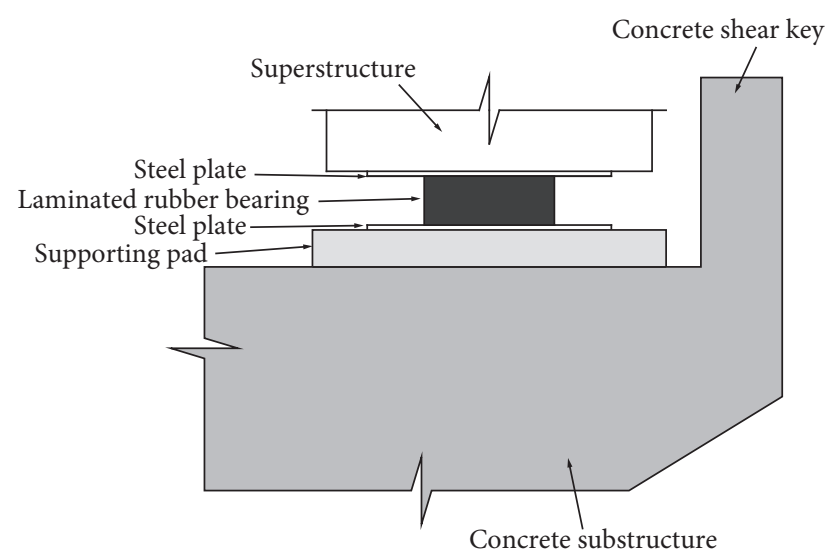

FIgURE 1: Layout of laminated-rubber bearings.

could be approximated as a linear elastic response, with an effective shear modulus in the range of $610-1100 \mathrm{kPa}$. The sliding coefficients of friction were observed to be inversely related to the normal force and positively related to the sliding velocity.

Considering the potential seismic damage of smallto-medium-span highway bridges with laminated-rubber bearings, some restraining devices have been proposed to improve the seismic performance of these bridges, such as yielding steel dampers $[11,12]$, using which the seismic girder displacement can be effectively controlled, while the bridges can achieve a reasonable balance between the bearing displacements and substructure seismic demands. Additionally, some studies [13-16] showed that cable restrainers could reduce the residual displacement of bridge bearings under earthquake loadings. Won et al. [14] studied the seismic response of a multispan simply supported bridge with cable restrainers. Their results showed that the relative displacement between the abutment and the next pier was effectively controlled, thus preventing the span from collapsing. However, few studies have investigated the effect of laminated-rubber bearings associated with restrainers on the seismic performance of skew bridges.

The design of skew bridges is often dictated by the orientation of the roadway that includes the bridge relative to the orientation of natural (rivers) and man-made (other roads) objects. Numerous studies [17-23] were conducted on the seismic response of skew bridges after the 1971 San Fernando, 1994 Northridge, and 2010 Chile earthquakes. Skewed bridges exhibit a significantly more complex seismic response than do the straight bridges. It was found that an in-plane rotation of the decks in skew bridges might cause large torques in the columns, thus making them more vulnerable. Moreover, a large skew is likely to increase the relative displacements between the girders and abutments, thus making skew bridges more vulnerable to unseating and collapse. To understand the unseating mechanism of a skew bridge with seat-type abutments, $\mathrm{Wu}$ et al. [24, 25] performed shake table tests of four single-span bridge models with skew angles of 0 (straight), 30,45, and 60 . Based on the test results on the unseating mechanism, it was further concluded [26] that the obtuse corner of the superstructure of a skew bridge engaged the adjacent back wall, and the superstructure then rotated about this corner. The impact of the span against the back wall was then followed immediately by a rebound away from the wall, and the span continued to rotate in the same direction in free vibration about the center of the stiffness of the substructure. Most of these aforementioned studies only focused on the seismic behavior of single-span skew bridges or two-span shew bridges with rigid girder-deck connections. Rasouli and Mahmoodi [27] assessed the effect of skewness and number of spans on the seismic behavior of multispan skew bridges with rigid girder-deck connections using a modal pushover analysis. In their study, an increase in the number of spans decreased the deck rotation responses at the abutments and the adverse effect of skewness.

For a multispan skew girder bridge with laminatedrubber bearings, bearing sliding could occur under strong earthquakes, which might change the seismic response of the bridge and lead to a seismic damage. However, little research has been carried out on this type of bridges. This study presents an investigation of the seismic performance of a multispan skew bridge with laminated-rubber bearings, which suffered seismic damage during the 2008 Wenchuan earthquake. To understand the seismic response of the bridge, a nonlinear analysis was carried out using the finite element method. In addition, parametric studies, including bearing types, skew angle, friction coefficient, and cable restrainers, were conducted, and measures to improve the seismic performance of the bridge were also identified.

\section{Background and Ground Motions}

2.1. Prototype Bridge. To achieve the objectives of this study, the Duxiufeng Bridge, located in Wenchuan, China, was adopted as the research object. This bridge was approximately $15.3 \mathrm{~km}$ from the epicenter and $5.7 \mathrm{~km}$ from the fault in the 2008 Wenchuan earthquake. The bridge has 6 spans with a total length of $188.06 \mathrm{~m}$, and each span is $30 \mathrm{~m}$ in length. Figure 2 shows the elevation and plan view of the bridge. The superstructure is supported on five bents, each consisting of two $1.5 \mathrm{~m}$ diameter columns. Figure 3 shows a typical bent section. The heights of the columns from the top of the footing to the bottom of the cap are 8.30, 11.49, 13.01, 14.29 , and $14.28 \mathrm{~m}$ for bents 1 to 5, respectively. Each column is an extension of a $1.8 \mathrm{~m}$ diameter pile. The top of the piles in each bent is linked by a transverse beam with a cross-section of $1.3 \times 1.5 \mathrm{~m}$. The lengths of the piles are 43.25 , $41.30,38.00,27.00$, and $27.30 \mathrm{~m}$ for bents 1 to 5 , respectively. The height and width of the bent cap are $1.5 \mathrm{~m}$ and $1.8 \mathrm{~m}$, respectively. The site consists mostly of gravel and sand, and the site class of the bridge is Type II according to the Chinese Guidelines for seismic design of highway bridges [28]. For the superstructure, four identical simply supported I-Shaped girders are located in each span, and two continuous decks with a width of $8.5 \mathrm{~m}$ each are placed on the three left and right spans. Expansion joints with a length of $80 \mathrm{~cm}$ are used at bent 3 and the abutments. The three left spans are slightly curved with a radius of $200 \mathrm{~m}$, while the three right spans are straight. The skew angle is $47^{\circ}$. Polytetrafluoroethylene 


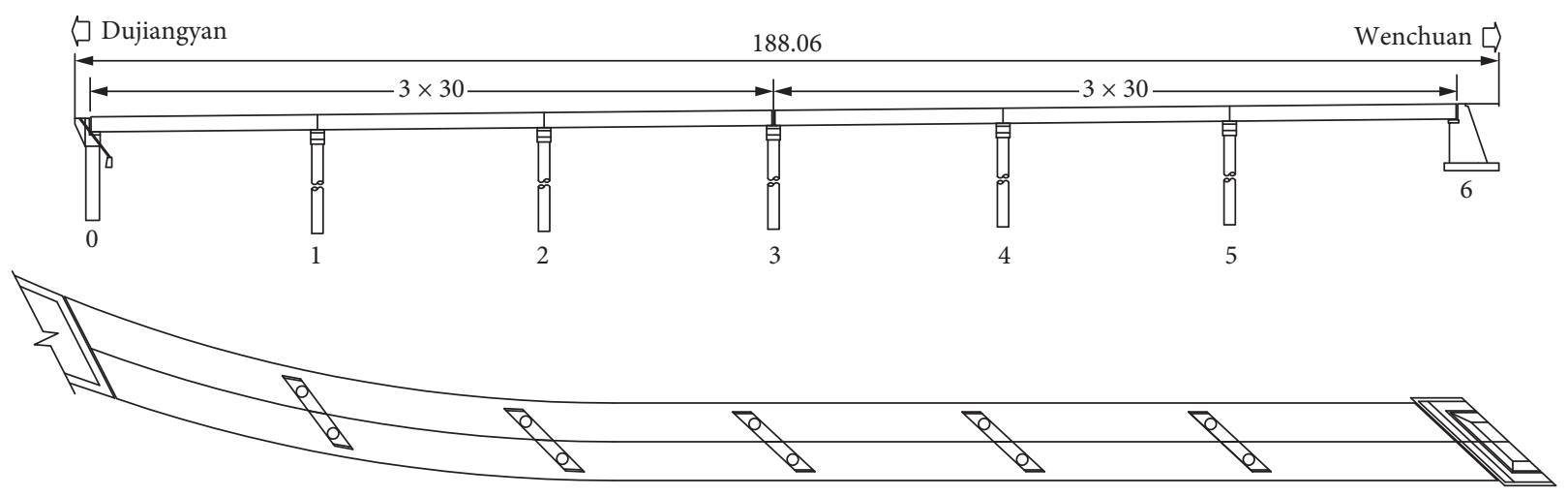

Figure 2: Elevation and plan view of Duxiufeng Bridge (unit: m).

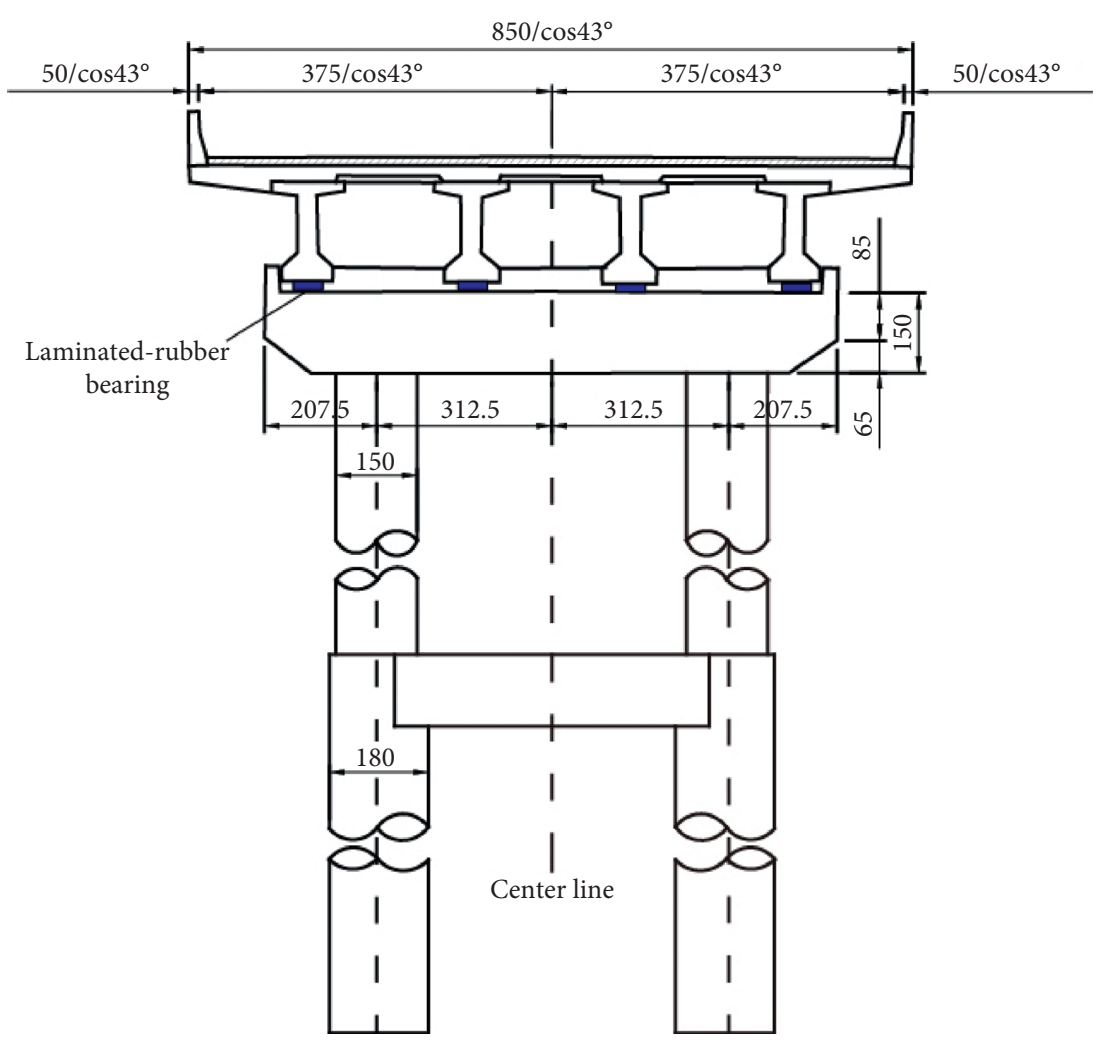

Figure 3: Typical bent section (unit: $\mathrm{cm}$ ).

(PTFE) sliding bearings with a small friction coefficient are used at the abutments and bent 3, so that a thermal movement of the girder is allowed. Laminated-rubber bearings support the girders directly at the other bents without any other connections. All the bearings allow sliding once the friction forces between the girders and bearings are exceeded by any horizontal forces, such as seismic forces. This bearing placement is a conventional design practice for small-to-medium-span highway bridges in western China, considering the low project costs and construction convenience. These bearings will fail when the relative displacement between the girder and the bearing is large enough to cause the girder to fall off from the bearing. To prevent the girder from falling off the Duxiufeng bridge caused by a failure of the bearing, the distances from the edges of the girder to the edge of the bearing in the longitudinal and transverse directions are 85 and $75 \mathrm{~cm}$, respectively; these calculations were made based on the Chinese Guidelines for seismic design of highway bridges [28].

Figures 4(a) and 4(b) show an overview of the Duxiufeng Bridge after the 2008 Wenchuan earthquake. Figures 4(c) and $4(\mathrm{~d})$ show the transverse residual displacement between two adjacent decks after the earthquake. In addition, the expansion joints at the abutment and bent 3 were damaged and had to be replaced. To this end, this bridge was selected as the prototype bridge in this study to investigate the seismic response of skew bridges with laminated-rubber bearings. 


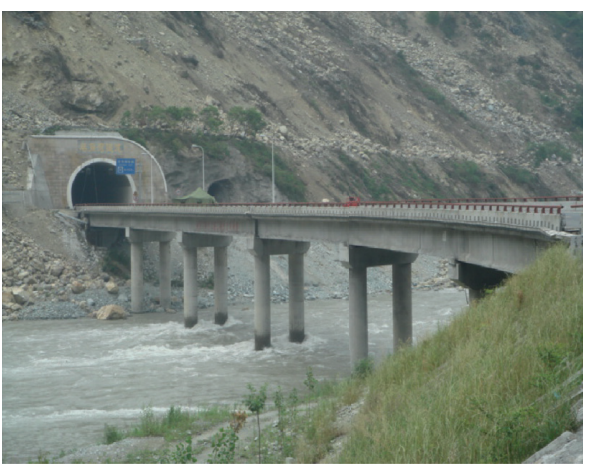

(a)

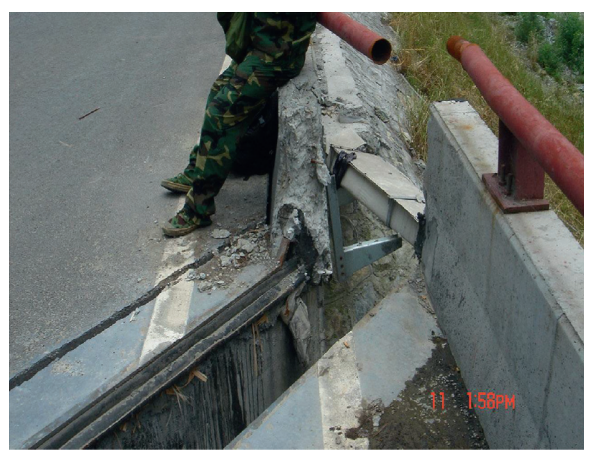

(c)

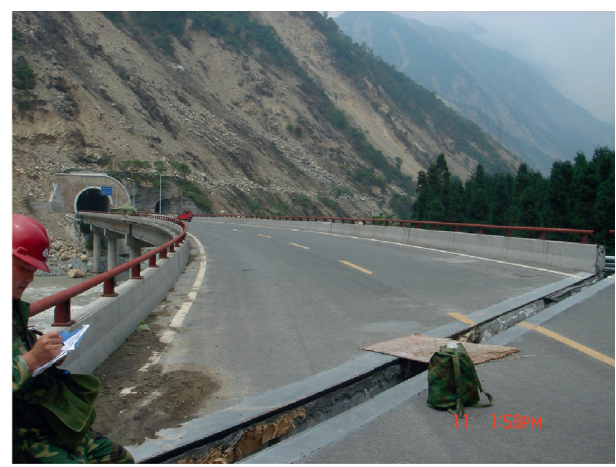

(b)

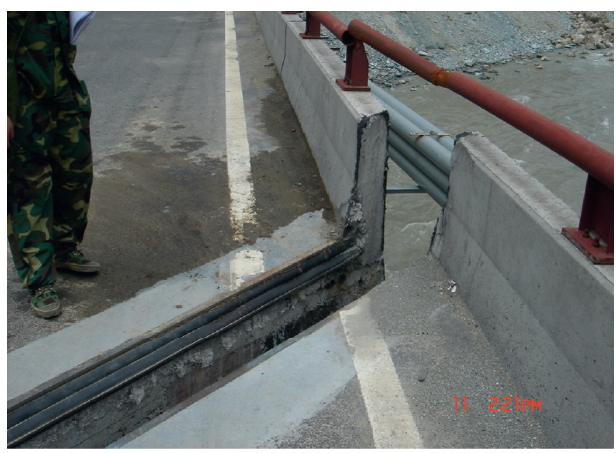

(d)

Figure 4: Photographs of the Duxiufeng Bridge after the 2008 Wenchuan earthquake. (a) Photographs of the bents. (b) Photographs of the deck. (c) Transverse residual displacement at abutment 0. (d) Transverse residual displacement at bent 3.

2.2. Ground Motions from the 2008 Wenchuan Earthquake. To simulate as accurately as possible, the actual seismic response of the Duxiufeng Bridge under the 2008 Wenchuan earthquake and acceleration time histories (Figure 5) recorded at the Wolong station, approximately $30 \mathrm{~km}$ from the bridge, were used to conduct a nonlinear analysis of the bridge. The peak ground acceleration (PGA) was the largest among all the records in the 2008 Wenchuan earthquake [7]. The PGAs recorded in the EW, NS, and UD directions were $0.957 \mathrm{~g}, 0.653 \mathrm{~g}$, and $0.948 \mathrm{~g}$, respectively. 0.1 and $25 \mathrm{~Hz}$ bandpasses were applied to filter the original records. The part of the record used in the analysis was from 20 to $70 \mathrm{~s}$. The three records were applied simultaneously. The corresponding acceleration response spectra are shown in Figure 6.

The longitudinal direction of the bridge is $\mathrm{NW} 10^{\circ}$, and the global coordinate system of the model was taken as follows: the X-, Y-, and Z- axes were along the longitudinal, transverse, and vertical directions of the bridge, respectively. Therefore, the NS record with an angle of $10^{\circ}$ to the $X$-axis was taken as the longitudinal input, and the EW record with an angle of $10^{\circ}$ to the $Y$-axis was taken as the transverse input. The vertical motion was also applied.

\section{Finite Element Model}

3.1. Modelling of the Superstructure. To understand the seismic response of the bridge during the earthquake, a detailed finite element model was developed using a
SAP2000 software [29]. From a comparative study, Meng and [20] concluded that the effect of the flexibility of the superstructure was significant and should not be ignored in the dynamic analysis because the use of the rigid deck or stick model in the dynamic analysis of skew bridges with large skew angles would lead to inaccurate axial forces in the columns during an earthquake. Therefore, the superstructure was modelled using a grid system that represented the beam's flexibility. In each span, four elastic beams were used to model the I-Shaped girders. The stiffness of the deck was included by enlarging the flange of the girders. Rigid transverse elements were assigned to the nodes to simulate the high in-plane stiffness of the deck.

3.2. Modelling of the Bents. Plastic hinges were assigned to the top and bottom of the columns. The plastic hinge sections consisted of three types of fibers: confined concrete, unconfined concrete, and longitudinal bars. The Mander [30] model was used to model the unconfined and confined concrete. The hinge length $\left(\mathrm{L}_{\mathrm{p}}\right)$ was calculated as follows based on [28]:

$$
L_{p}=\min \left(0.08 H+0.022 f_{y} d_{s} \geq 0.044 f_{y} d_{s}, \frac{2}{3} b\right),
$$

where $H$ is the distance from the top or bottom to the point where the moment is zero; $b$ is the minimum cross-sectional dimension or the diameter of the circular section; $f_{y}(\mathrm{MPa})$ is the specified steel bar yield strength, and $d_{s}$ is the bar diameter. The concrete grade in the bents was C30 with a 

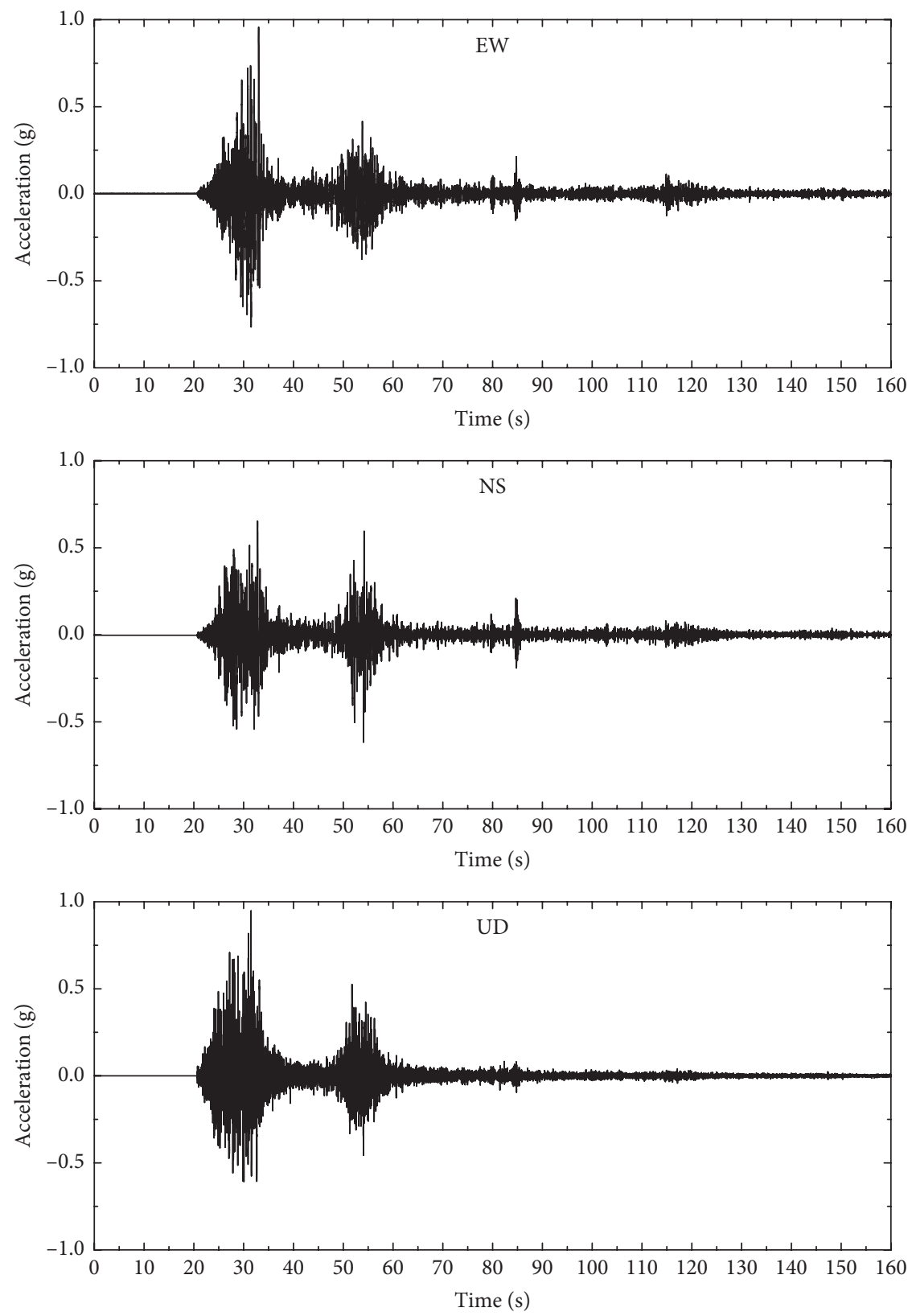

FIgURE 5: Acceleration time histories of Wolong records.
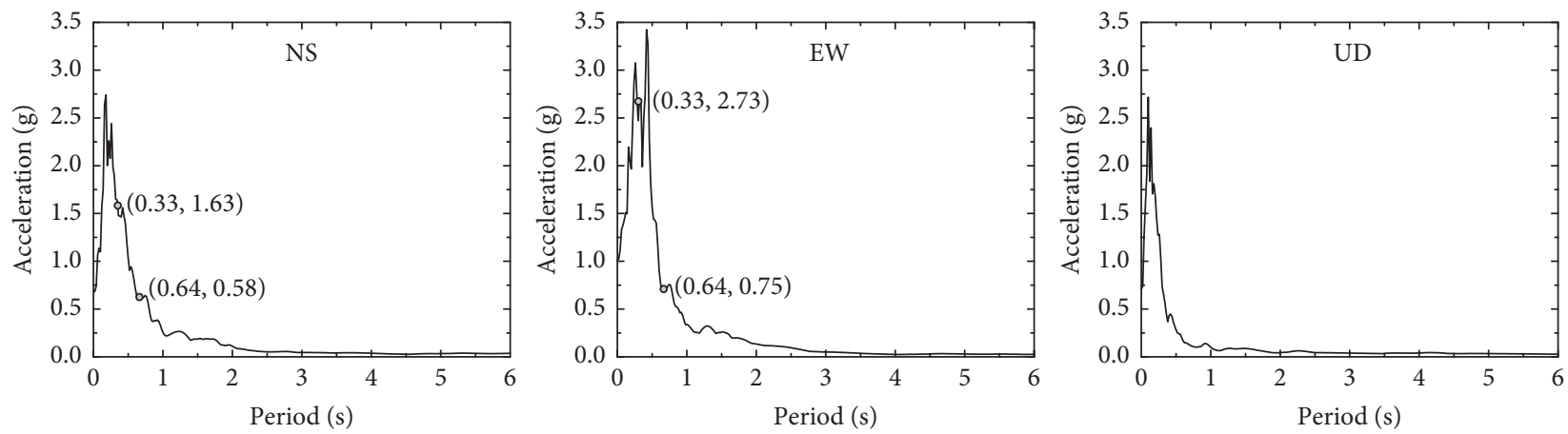

Figure 6: Acceleration response spectra of Wolong records. 
specified compressive strength of $20.1 \mathrm{MPa}$ [31]. The steel grades of the longitudinal and transverse bars were HRB335 and R235, respectively, and the yield strengths of these steel grades were 335 and $235 \mathrm{MPa}$, respectively [31]. The locations of the hinges were defined in the middle of the plastic hinge length. The bent caps were modelled as elastic elements.

3.3. Modelling of the Bearings. As stated before, the links between girders and bents are laminated-rubber bearings without any other connections. Therefore, friction forces are the only horizontal forces. No tension force can be transmitted through the bearings. The friction isolator link in SAP2000 was used to simulate this mechanical behavior. Friction factors were assigned in the horizontal direction to calculate the horizontal forces based on the normal force on the bearing. The normal force $(P)$ is always nonlinear:

$$
P= \begin{cases}k d, & \text { if } d<0, \\ 0, & \text { otherwise, }\end{cases}
$$

where $k$ is the compressive stiffness of the laminated-rubber bearing and $d$ is the normal deformation of the bearing.

To simulate the sliding behavior of elastomeric bearings, an analytical model considering the effect of the normal pressure is shown in Figure 7. The model incorporates two components: elastic shear stiffness $\left(K_{e}\right)$ and sliding coefficient of friction $(\mu)$.

The value of $\mu$ between the laminated-rubber bearings and concrete girders was taken as 0.3 from the experimental results of Huang [32], while that between the PTFE sliding bearings (at the abutments and bent 3 ) and concrete girders was taken as 0.02 . The elastic shear stiffness $\left(K_{e}\right)$ of elastomeric bearings can be calculated using the following equation:

$$
K_{e}=\frac{G A}{\sum t},
$$

where $G$ is the shear modulus of the rubber, $A$ is the area of the bearing, and $\sum t$ is the total thickness of the rubber layers in the elastomeric bearings.

3.4. Modelling of the Expansion Joints. Gap elements were used to model the pounding effect between the superstructure segments at bent 3 and between the superstructure and the abutments. The initial gap was set as $8 \mathrm{~cm}$, which is the standard expansion joint gap length in bridges. The girder axial stiffness was used as the gap element compressive stiffness.

3.5. Modelling of the Foundations and the Abutments. Linear rotational and translational springs were used to model the bent foundation to account for the soil-pile interaction. The stiffnesses of the bent foundations were calculated by considering the arrangement of piles and soil information at the bridge site, based on the Chinese Guidelines for seismic design of highway bridges [28].

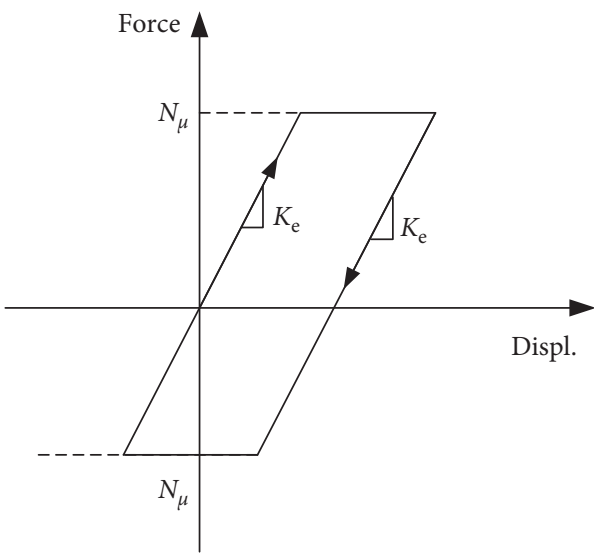

FIgURE 7: Analytical model of the sliding of elastomeric bearings.

Longitudinal linear springs were used to model the abutment to account for the abutment-superstructure interaction upon the gap closure. The transverse springs were not considered because there were no concrete shear keys at the abutments. The stiffnesses of the abutments were determined using the California Department of Transportation (Caltrans) guidelines [33]. The initial stiffness, yield force, and yield displacement for the abutment spring were $133.66 \mathrm{kN} / \mathrm{mm}, 6168 \mathrm{kN}$, and $46 \mathrm{~mm}$, respectively. The finite element model is shown in Figure 8.

\section{Response Analysis}

4.1. Dynamic Characteristics. The dynamic response of a structure is generally based on its natural vibration modes. Therefore, the natural periods and mode shapes for the first seven modes of the bridge were calculated (see Table 1). The results indicate that the fundamental mode of the bridge was the in-plane rotation of the superstructure, which was mainly because of the large skewness of the bridge and unsymmetrical column heights. Under excitations with predominant periods close to the in-plane rotation periods, the rotation response would be significant and cause relatively large displacements compared with nonskew bridges. As the heights of the columns of the three right bents were larger than those of the two left bents, the natural periods of the former were longer than those of the three left spans. For the 7 th mode, the longitudinal vibration of bent 3 was similar to that of a cantilever beam because the PTFE sliding bearings had small friction forces and provided minimal constraint to the bent.

4.2. Results of Nonlinear Analysis. First, a nonlinear static pushover analysis was performed for each bent, considering the dead load effect of the bridge. The pushover results are listed in Table 2 . The displacement ductility capacity is the ratio of the ultimate displacement to the yield displacement. It can be seen that the yield displacements increased as the bent heights increase, while the horizontal load capacity decreased. The longitudinal ductility and displacement capacities were larger than those in the transverse direction, 


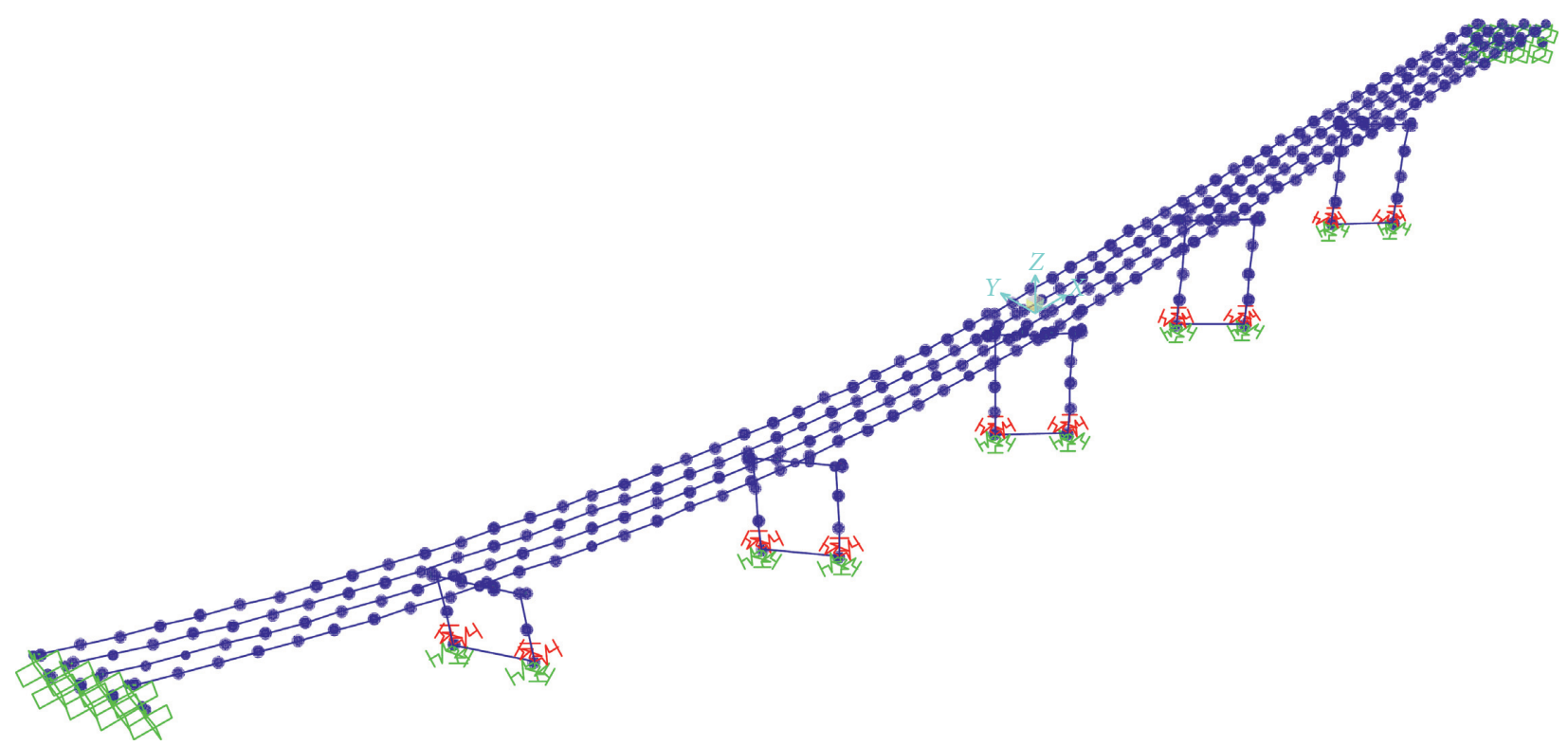

FIGURE 8: Finite element model.

TAble 1: First seven natural modes of the bridge.

\begin{tabular}{lccc}
\hline Mode no. & Periods (s) & Frequency (Hz) & Mode description \\
\hline 1 & 2.462 & 0.406 & In-plane rotation (right three spans) \\
2 & 2.087 & 0.479 & In-plane rotation (left three spans) \\
3 & 1.754 & 0.570 & Longitudinal vibration (right three spans) \\
4 & 1.430 & 0.699 & Longitudinal vibration (left three spans) \\
5 & 1.329 & 0.752 & Transverse vibration (right three spans) \\
6 & 1.108 & 0.902 & Transverse vibration (left three spans) \\
7 & 0.645 & 1.551 & Longitudinal vibration of bent 3 \\
\hline
\end{tabular}

TABle 2: Pushover results of the bents.

\begin{tabular}{|c|c|c|c|c|c|c|}
\hline \multirow{2}{*}{ Bent no. } & \multicolumn{2}{|c|}{ Yield displacement (mm) } & \multicolumn{2}{|c|}{ Displacement ductility capacities } & \multicolumn{2}{|c|}{ Maximum horizontal force $(\mathrm{kN})$} \\
\hline & Longitudinal & Transverse & Longitudinal & Transverse & Longitudinal & Transverse \\
\hline 1 & 40 & 10 & 6.90 & 2.67 & 1022 & 1025 \\
\hline 2 & 60 & 15 & 7.00 & 3.05 & 765 & 767 \\
\hline 3 & 80 & 20 & 7.48 & 3.17 & 653 & 654 \\
\hline 4 & 100 & 25 & 5.88 & 2.79 & 619 & 619 \\
\hline 5 & 100 & 25 & 6.40 & 2.88 & 608 & 608 \\
\hline
\end{tabular}

which meant that the bents were more vulnerable to the loadings in the transverse direction.

A nonlinear analysis was conducted to study the seismic response of the skew bridge using the finite element method. As representative results, the displacement time histories of the bent tops for bents 2 and 4 in the two horizontal directions are illustrated in Figure 9. It can be seen that the displacement of bent 2 (a relatively short bent) in the transverse direction was smaller than the longitudinal displacement. However, this trend was reversed in the taller bents (e.g., bent 4). The yield displacements in the longitudinal and transverse directions were 60 and $15 \mathrm{~mm}$, respectively, for bent 2 , and 100 and $25 \mathrm{~mm}$, respectively, for bent 4 . The results also show that, in the longitudinal direction, the bents remained elastic; however, they yielded in the transverse direction with displacement ductility demands of 1.97 and 2.91 for bents 2 and 4, respectively. The ductility demands were smaller than the corresponding calculated capacities for bents 2 and 4. As shown in Figure 9, there was no significant residual displacement in either direction.

Figure 10 compares the displacement ductility demands and ductility capacities of the bents. $\mu_{D}$ is the displacement ductility demand, and $\mu_{C}$ is the calculated displacement ductility capacity (See Table 2). The displacement ductility demand $\mu_{D}$ is the ratio of the maximum seismic displacement of the bent to the corresponding yield displacement. The bent remains elastic if $\mu \leq 1$. It can be seen that all the bents remained elastic in the longitudinal direction except bent 1 , while, for the transverse direction, all the bents yielded; however, the ductility demands 


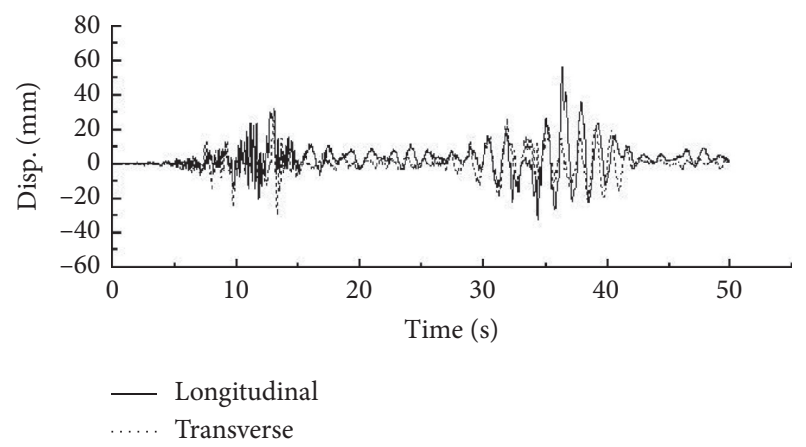

(a)

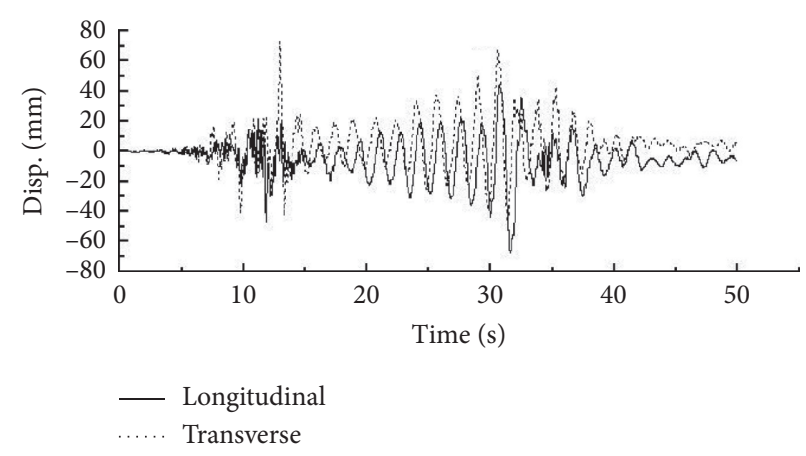

(b)

Figure 9: Displacement time histories of the bent tops. (a) Bent 2. (b) Bent 4 .

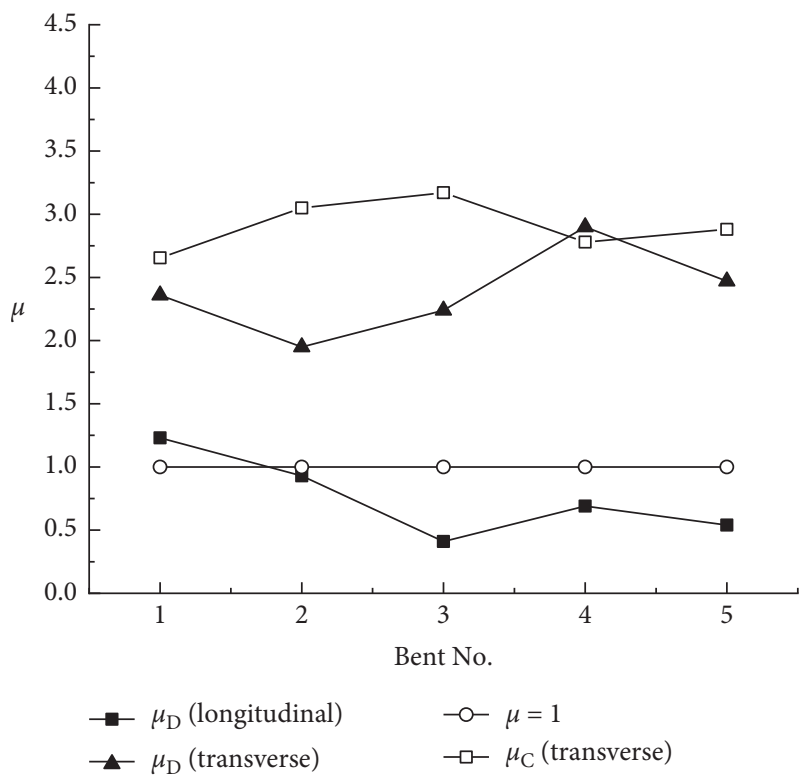

Figure 10: Ductility demands of bents.

were smaller than the corresponding ductility capacities for all the bents except bent 4 . It is interesting to note that even though the friction coefficient of the bearings on bent 3 was small and hence, only a little friction force could be transferred from the superstructure to the bent through the bearing, the displacement ductility demands of bent 3 in both the directions were almost the same as the those of the other bents. This result can be explained by the response spectra (Figure 6). As stated above, there was almost no constraint at the top of bent 3 , and it could vibrate as a cantilever system. The first two natural modes of bent 3 were longitudinal and transverse modes with periods of 0.64 and $0.33 \mathrm{~s}$, respectively. From the response spectra, it is evident that the corresponding accelerations at these periods were relatively large, as shown in Figure 5. The other bents are constrained to the superstructure through the friction of the bearings, and the natural vibration periods (the transverse rotation periods of the bridge, as shown in Table 1) were relatively large. Furthermore, the spectral accelerations were much smaller during these periods. Therefore, displacements generated with large accelerations and small masses (bent 3) were approximately the same as those generated with small accelerations and large masses (the remaining bents).

The maximum residual displacements of the bearings in the longitudinal and transverse directions were 85.9 and $155.5 \mathrm{~mm}$, respectively. The maximum axial deformation of the gap elements was $84.5 \mathrm{~mm}$, and the corresponding force was $1546 \mathrm{kN}$. Pounding occurred at the left side of bent 3 due to the in-plane rotation of the decks. The calculated residual relative displacements between two adjacent decks are listed in Table 3. It can be seen that the maximum residual relative displacement in Table 3 was $110.4 \mathrm{~mm}$ appearing at bent 3, which was much smaller than the measured value. Although the error between the calculated maximum residual displacement and the real value was relatively large, the calculated maximum residual displacement between the two adjacent decks also happened at bent 3 of the Duxiufeng Bridge, which reflected the real seismic behavior of this skew bridge under the 2008 Wenchuan Earthquake that the residual displacement between span 3 and span 4 was the largest and may cause severe seismic damage. The possible explanation for the error is that the ground motion used in the work was not the real ground motion at the bridge site, and the recorded station of the ground motion was approximately $30 \mathrm{~km}$ far from the bridge site. The characteristics of the ground motion might be influenced by some factors, such as the landform of the bridge site that was different from the recorded site.

(1) In the longitudinal direction, the fixed-pin bearings were used at bents 2 and 4 , and roller bearings, which allow the movement of the girder, were used at other bents. In the transverse direction, the girder was restrained by bearings at the other bents.

(2) In the longitudinal direction, the situation of the bearings was the same as in the first case; however, in the transverse direction, the movement of the girder was free at the other bents.

\subsection{Postearthquake Repair}

4.3.1. Effect of Bearing Types. From the postearthquake disaster investigation and the results from the numerical simulation, it can be seen that the Duxiufeng Bridge under 
TABLE 3: Calculated residual relative displacement between two adjacent decks.

\begin{tabular}{|c|c|c|c|}
\hline \multicolumn{2}{|c|}{ Position } & Longitudinal (mm) & Transverse $(\mathrm{mm})$ \\
\hline \multirow{2}{*}{ Abutment 0} & Right side & 64.7 & 24.8 \\
\hline & Left side & 83.4 & 43.7 \\
\hline \multirow{2}{*}{ Bent 3} & Right side & 2.0 & 110.4 \\
\hline & Left side & 22.3 & 87.0 \\
\hline \multirow{2}{*}{ Abutment 6} & Right side & 66.1 & 35.9 \\
\hline & Left side & 58.5 & 28.8 \\
\hline
\end{tabular}

the Wenchuan earthquake suffered severe seismic damage, including a large residual displacement, girder pounding at bent 3 , and yielding of rebars in bents, which hampered the postearthquake functioning of the bridge. To repair this bridge, all the damaged bearings needed to be replaced. Taking this into consideration, a comparison of different bearing types was analyzed to obtain a feasible plan to improve the seismic performance of the bridge at a low project cost. In this analysis, the other two common bearing types were selected, based on the current design practice of small-to-medium-span bridges in China, as described below:

To facilitate the discussion, the bridge model with the first bearing combination was labelled as the "pin-roller bearing," and the one with the second type was labelled as the "pin-free bearing." The model with the actual bearing placement used in the Duxiufeng Bridge was referred to as a "rubber bearing."

Figure 11 shows the displacement ductility demands of the bents for different bearing types. The pin-roller bearing experienced the largest bent displacement ductility demands in the longitudinal direction. None of the bents in the other two models yielded in the longitudinal direction. The in-plane rotation of the superstructure was restrained because the transverse movement was restrained. It is seen that the transverse restraint led to large bent forces in both directions, which increased the displacement ductility demands in the bents. The differences in the displacement ductility demands in the longitudinal direction between the pin-free and rubber bearings were relatively small. The pin-roller bearing also had the largest displacement ductility demands in the transverse direction of all the bents, except for bents 4 and 5. In contrast, the displacements of the pin-free bearing were slightly larger than those of the rubber bearing at the fixed-pin bents (bents 2 and 4). Therefore, the pin-free and rubber bearing models were preferred for controlling the damage in the bents under the Wolong records.

The maximum seismic displacements of the bearings for different bearing types are listed in Table 4 . These results indicate that the longitudinal and transverse maximum displacements for the bridge with laminated-rubbers were larger than those of the others. The results for the pin-free bearing model were approximately one-half of the results for the rubber bearing model. For the pin-roller bearing model, the longitudinal displacement was slightly larger than that for the rubber bearing model, and the transverse displacement was zero because the bearings were fixed in the transverse direction. The results indicate a significant reduction in both the longitudinal and transverse maximum displacements for the pin-free model compared with those of the rubber bearing model. Therefore, the pin-free bearing was recommended for the Duxiufeng Bridge to control the seismic displacements.

4.3.2. Effect of Cable Restrainers. The skew bridge with laminated rubber bearings suffered from the possibility of the girder falling off under strong earthquakes; therefore, seismic devices are needed to improve its seismic performance. Considering the feasibility and the budgetary constraints of the postearthquake repair for the Duxiufeng Bridge, cable restrainers with elastic behavior were selected as the seismic control device. The cable restrainers were assumed to be installed at the expansion joints at abutments 0 and 6 , and bent 3 . The layout of the cable restrainers is shown in Figure 12. Two cable restrainers were symmetrically arranged at each abutment expansion joint, attaching the girders to the abutment. Four more cable restrainers were symmetrically arranged at the middle expansion joint, attaching spans 3 and 4 to bent 3 . The cable restrainer stiffness was assumed to be the same at different locations. Although the minimum restrainer stiffness suggested was $2.5 \mathrm{kN} / \mathrm{mm}$ according to a study by Saiidi et al. [13], stiffness values of $1.25,2.5,5$, and $10 \mathrm{kN} / \mathrm{mm}$ were employed to perform a parametric study. Additionally, the elastic behavior of the cable restrainers is also shown in Figure 12. The initial slack of the cable restrainers was taken as zero to account for the extremely low temperature and the most critical condition for restrainer loading.

Figure 13 compares the maximum residual displacements of the bearings considering the cable restrainers with different stiffnesses; positions 0 and 6 represent abutments 0 and 6 , while positions 1 to 5 represent bents 1 to 5. In Figure 13(a), it can be seen that the longitudinal maximum residual displacements of the bearings without the cable restrainers were larger than those with the cable restrainers at positions 0 to 6 . In general, even a nominal cable restrainer (with a relatively small stiffness) could reduce these residual displacements by approximately $50 \%$ in most positions. With an increase in the stiffness, significantly complicated variations of the residual displacements were presented. Additionally, Table 5 shows the percentages of the decrease in the maximum residual displacements with different stiffnesses at positions 0,3 , and 6 because the seismic damage led by the residual displacements could appear at positions other than the above. The percentage of decrease, $\eta$, can be calculated using 


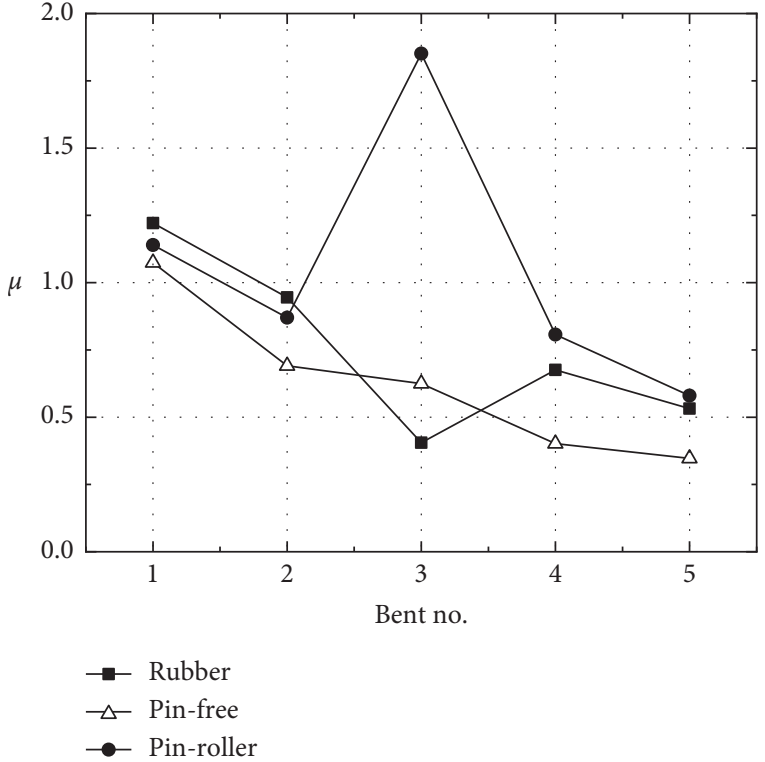

(a)

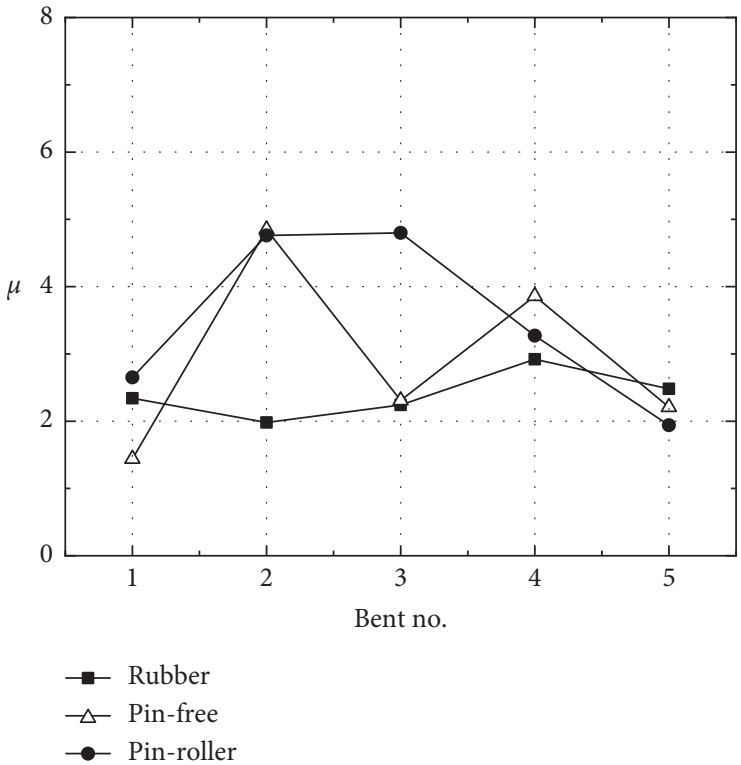

(b)

FIGURE 11: Displacement ductility demands of bents with different bearing types. (a) Longitudinal direction. (b) Transverse direction.

TABLE 4: Maximum seismic displacement of bearings for different bearing types.

\begin{tabular}{lcc}
\hline Bearing type & Longitudinal $(\mathrm{mm})$ & Transverse $(\mathrm{mm})$ \\
\hline Rubber & 119 & 229 \\
Pin-free & 68 & 118 \\
Pin-roller & 121 & 0 \\
\hline
\end{tabular}

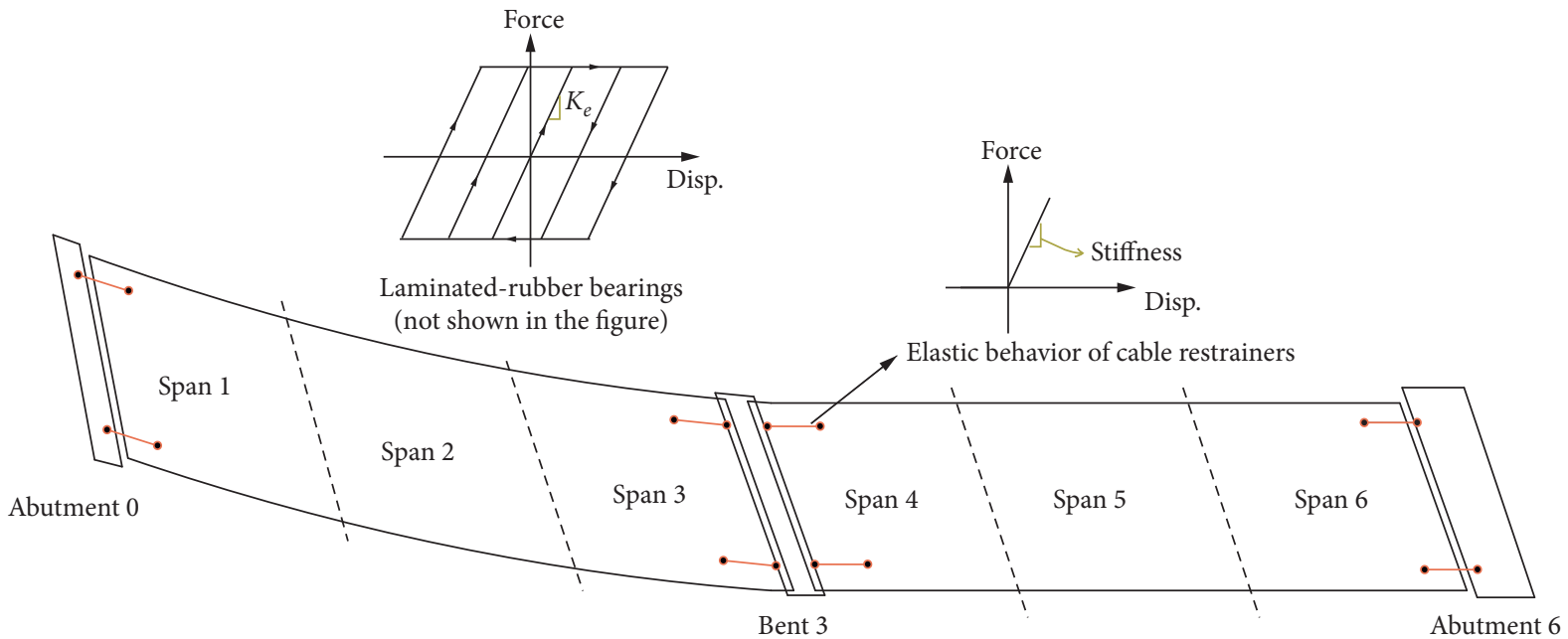

$\longrightarrow$ Cable restrainers

Figure 12: Layout of the cable restrainers for the Duxiufeng Bridge.

$$
\eta=\frac{D-D_{\text {cable }}}{D}
$$

where $D$ is the residual displacement of the bearing without the cable restrainers, while $D_{\text {cable }}$ is the residual displacement of the bearing with the cable restrainers. It can be seen that the residual displacement at position 6 was significantly affected by the cable restrainers as the minimum value of $\eta$ was larger than $60 \%$. When the stiffness was less than $5 \mathrm{kN} /$ $\mathrm{mm}$, the values of $\eta$ at 0 and 3 were smaller than $50 \%$. Based on these results, the stiffness of the cable restrainers used in the Duxiufeng Bridge should be equal or greater than $5 \mathrm{kN} /$ 


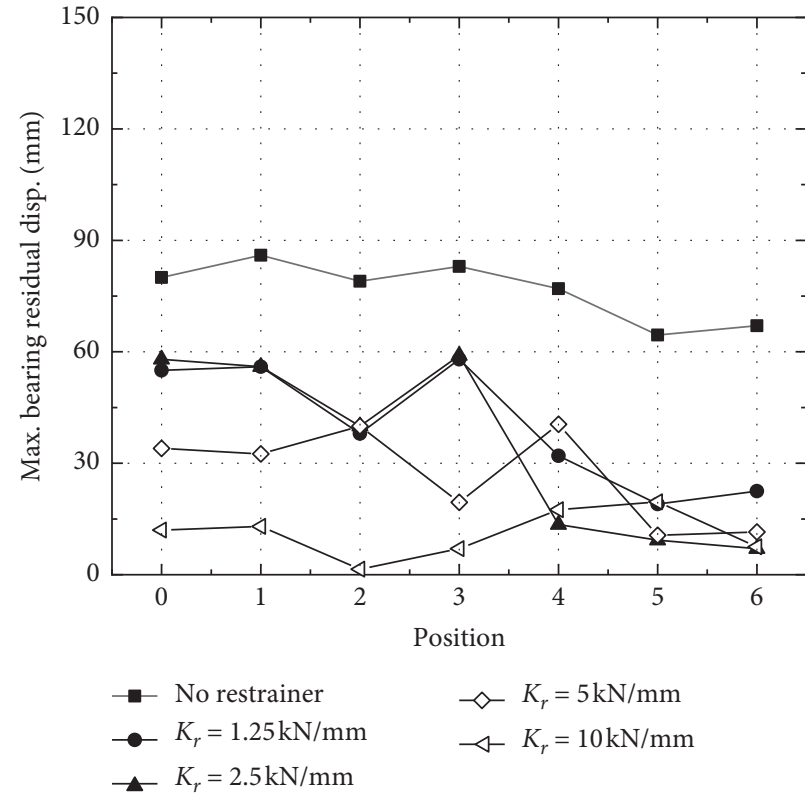

(a)

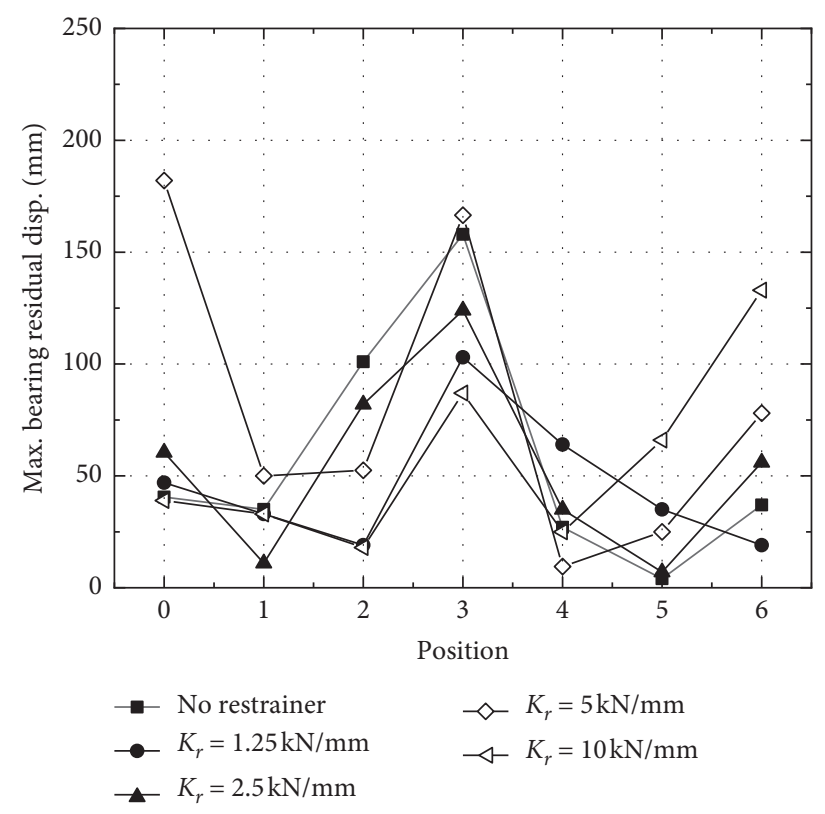

(b)

FIGURE 13: Comparison of maximum residual displacements of bearings. (a) Longitudinal direction. (b) Transverse direction.

TABle 5: Percentages of decrease in the maximum residual displacements of bearings.

\begin{tabular}{lcccc}
\hline \multirow{2}{*}{ Position } & \multicolumn{3}{c}{ Stiffness of cable restrainers } \\
& $1.25 \mathrm{kN} / \mathrm{mm}(\%)$ & $2.5 \mathrm{kN} / \mathrm{mm}(\%)$ & $5 \mathrm{kN} / \mathrm{mm}(\%)$ & 57.5 \\
$10 \mathrm{kN} / \mathrm{mm}(\%)$ \\
\hline Abutment 0 & 31.3 & 27.5 & 76.5 & 85.0 \\
Bent 3 & 30.1 & 28.9 & 82.8 & 91.6 \\
Abutment 6 & 66.4 & 89.6 & 72.3 & 88.8 \\
Average value & 42.6 & 48.7 & 88.5 \\
\hline
\end{tabular}

mm. In addition, for a given cable restrainer stiffness, the average value of $\eta$ was also calculated. With an increase in the stiffness, the average value increased, indicating that the cable restrainer with a larger stiffness could achieve a better performance for controlling the residual displacements of the bearings.

Figure 13(b) illustrates that the longitudinal cable restrainers had an insignificant effect on limiting the maximum transverse residual displacements of the bearings, and they might increase the displacements at some positions. Taking the cable restrainers with a stiffness of $5 \mathrm{kN} / \mathrm{mm}$ as an example, the longitudinal residual displacement at bent 3 decreased, while the transverse displacement increased. This was expected because the cable restrainers acted mainly in the longitudinal direction. Meanwhile, the biaxial horizontal input motion and rotation of the superstructure resulted in coupled longitudinal and transverse displacements of the superstructure. When the longitudinal movement was constrained, the girders tended to move transversely, which tended to amplify the rotation of the superstructure.

The maximum elongations of the cable restrainers were $84,77,70$, and $68 \mathrm{~mm}$ corresponding to stiffnesses of 1.25 , $2.5,5$, and $10 \mathrm{kN} / \mathrm{mm}$, respectively. These values were smaller than those of the yield displacement $(107 \mathrm{~mm})$ of the widely used cable restrainers [13], indicating that the cable restrainers could remain elastic during the earthquake.

\section{Parametric Analysis}

5.1. Ground Motions for Parametric Analysis. To further study the seismic performance of skew bridges with laminated-rubber bearings, the effects of the skew angle and friction coefficient were investigated in this study through a numerical analysis. Ten real earthquake records with the same seismic soil classification of the Duxiufeng Bridge were used in the analysis, including the Wolong records described in the previous section, as shown in Table 6. The other nine earthquake records were selected from the Pacific Earthquake Engineering Research Centre (PEER) ground motion database. For each record, all the three components were included in this analysis, and the input direction was the same as that specified in the previous section. Figure 14 shows the acceleration response spectra of the largest components of the ten records. In these analyses, the largest PGA of the three components was scaled to $0.957 \mathrm{~g}$, which is the same as the PGA of the Wolong records. The same scaling factor was also used for the other two components of each earthquake record. The seismic responses of the bridge 
TABLE 6: Earthquake records for seismic analysis.

\begin{tabular}{lccc}
\hline Earthquake & Year & Station name & Scale factor \\
\hline Wenchuan & 2008 & Wolong & 1.0 \\
Northridge & 1994 & Sylmar hospital & 1.136 \\
Loma prieta & 1989 & SF airport & 2.911 \\
Imperial valley & 1940 & El centro & 3.058 \\
Chi-Chi & 1999 & CHY025 & 5.921 \\
Kobe & 1995 & Kakogawa & 2.952 \\
Kobe & 1995 & KJMA & 1.147 \\
San Fernando & 1971 & Castaic old ridge route & 2.802 \\
Parkfield & 1966 & Cholame - Shandon array \#8 & 3.866 \\
Kern county & 1952 & Taft Lincoln school & 5.308 \\
\hline
\end{tabular}

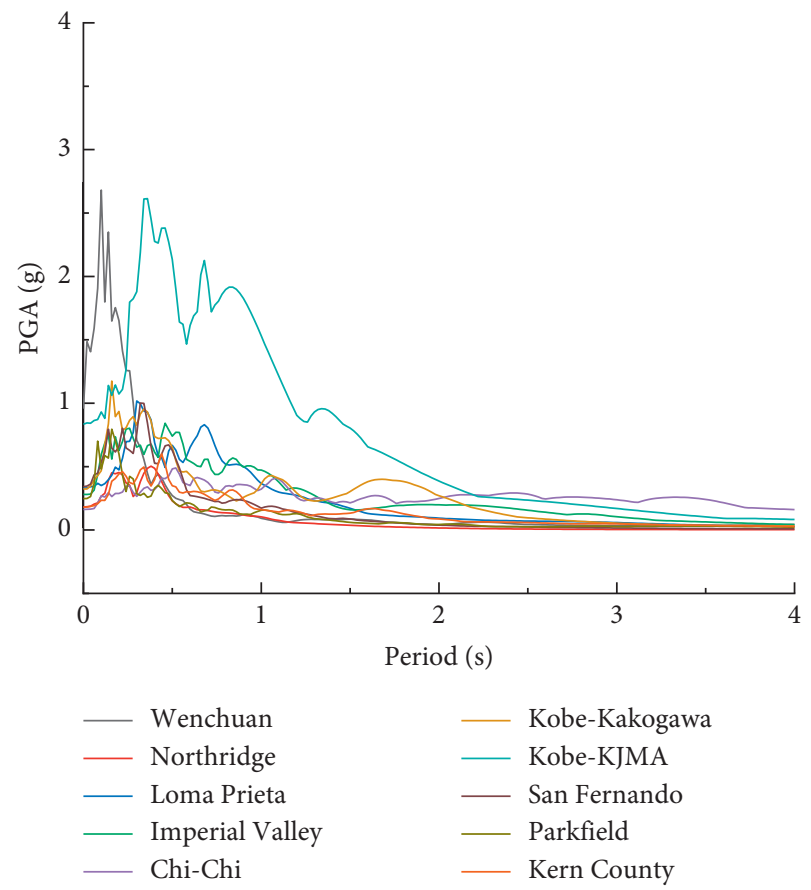

Figure 14: Acceleration response spectra of selected records.

under these records were averaged to ensure that the conclusions were independent of the input.

5.2. Effect of Skew Angle. The skew angle of the Duxiufeng Bridge was $47^{\circ}$. To study the effect of the skew angle on the dynamic responses of the bridge, different models with the same properties, but different skew angles $(15,30,47$, and $60^{\circ}$ ), were developed and analyzed. The dynamic characteristics and seismic responses were calculated to study the influence of the skew angle.

5.2.1. Dynamic Characteristics. The effect of the skew angle on the modal periods is shown in Figure 15. The results indicate that, with an increase in the skew angle, the periods of the first four modes were enlarged. This is because both the torsional stiffness of the bents and the in-plane rotational inertia of the superstructure increased with the skew angle; however, the increase in the torsional stiffness was smaller than that of the rotational inertia.

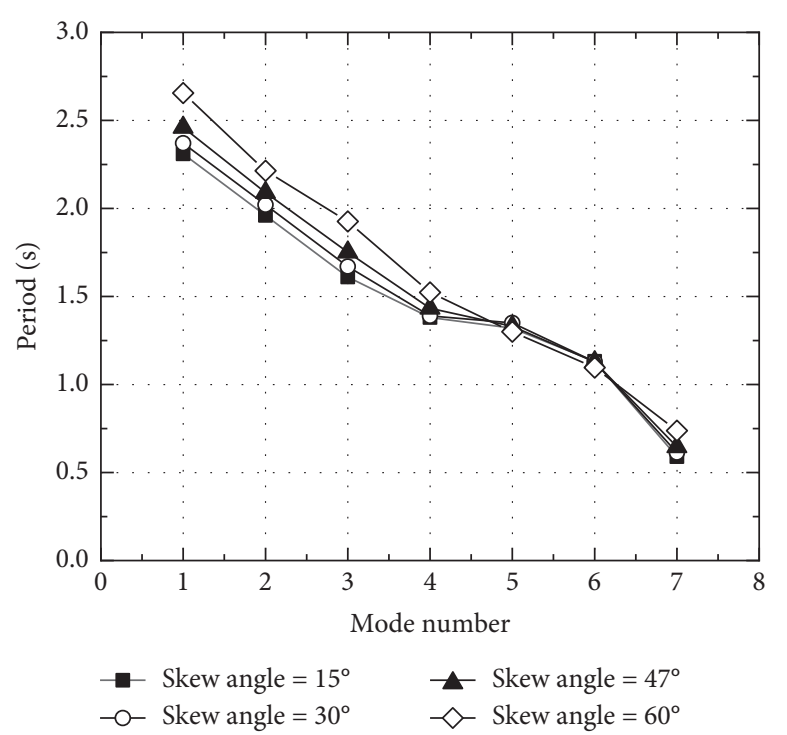

FIgURE 15: Comparison of modal periods with different skew angles.

5.2.2. Seismic Response. Figure 16 shows a comparison of the maximum and residual seismic displacements of the bearings with different skew angles. Avg. $(L)$ is the average value for all the bearings in the longitudinal direction; Avg. $(T)$ is the average value for all the bearings in the transverse direction; $\operatorname{Max}(L)$ is the maximum value for all the bearings in the longitudinal direction; and $\operatorname{Max}(T)$ is the maximum value for all the bearings in the transverse direction. It can be seen that, with an increase in the skew angle, the maximum and average values of the longitudinal maximum seismic displacements varied slightly, while the same in the transverse direction were significantly affected by the skew angle. For the residual displacement, the maximum and average values reached a minimum in both the longitudinal and transverse directions for a skew angle of $47^{\circ}$. Previous studies $[20,33]$ have pointed out that an increase in the skew angle increases the girder displacement response of the bridge. This conclusion was based on the investigations and numerical analyses on rigid-frame bridges. However, for the models analyzed in this study, sliding occurred between the bearings and girders, thus decreasing the in-plane rotation. Therefore, the effect of the skew angle on the seismic displacement response of the bridge with laminated-rubber bearings was less significant than that of a rigid-frame bridge.

The effect of skew angle on the displacement ductility demands of bents is shown in Figure 17. Generally, the skew angle has an insignificant influence on the ductility demands in the longitudinal direction if the skew angle is less than $47^{\circ}$. The ductility demands in bents 2,4 , and 5 in the model with a skew angle of $60^{\circ}$ were larger than those in the other models, indicating that taller bents and bents with laminated-rubber bearings were sensitive to a large skew angle compared with the shorter bents and bents with PTFE sliding bearings (bent 3). Sliding occurred in bent 3 , thus reducing the effect of the skew angle. For the 


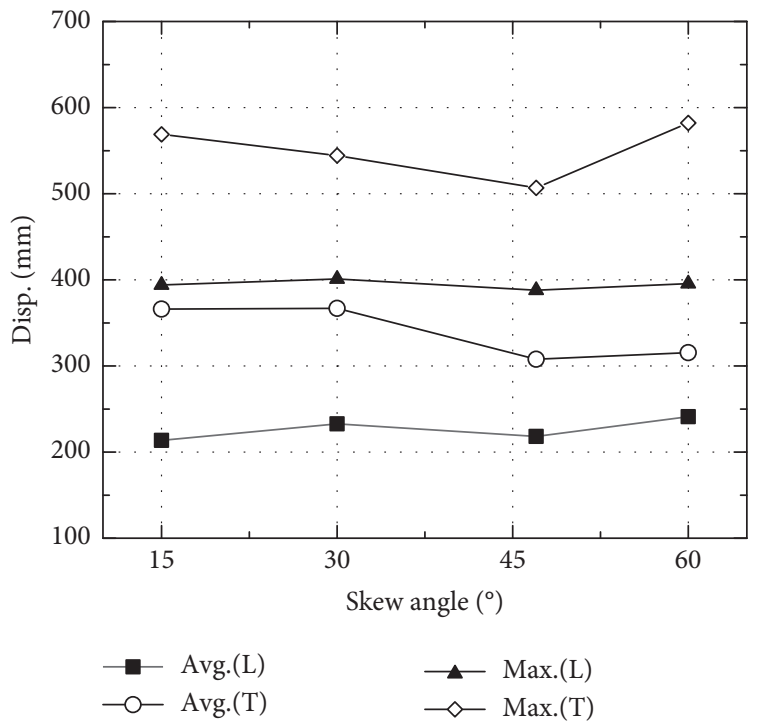

(a)

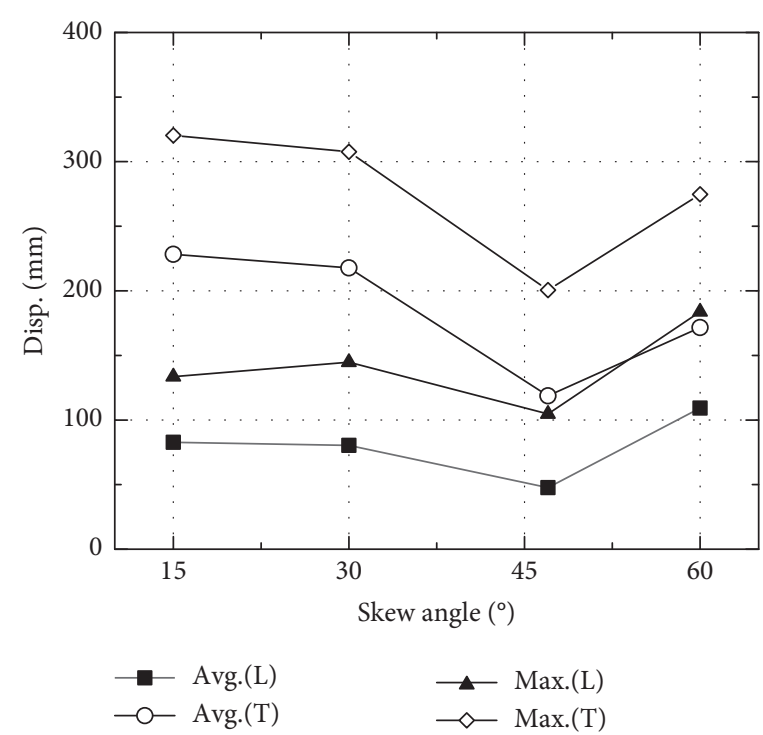

(b)

Figure 16: Comparison of seismic displacements of bearings with different skew angles. (a) Maximum displacement. (b) Residual displacement.

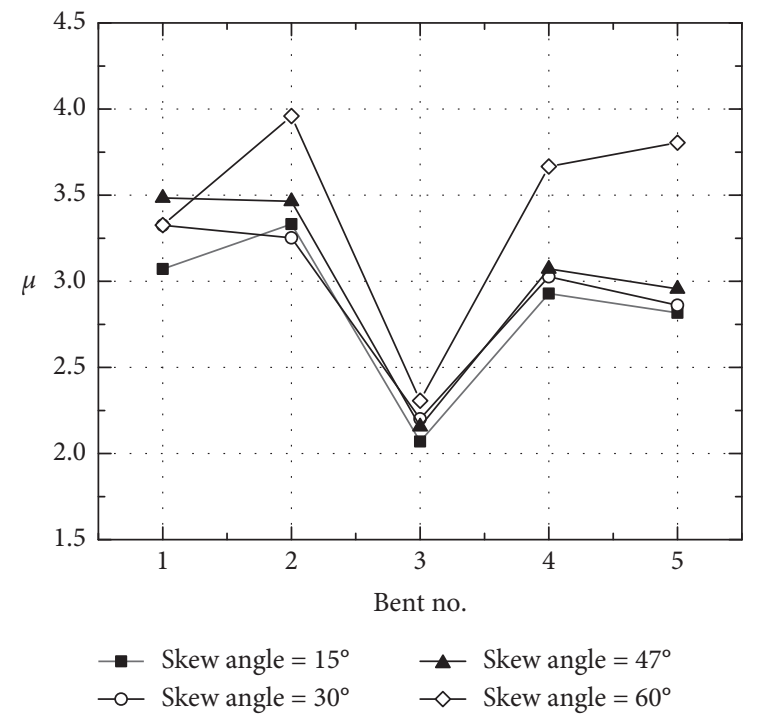

(a)

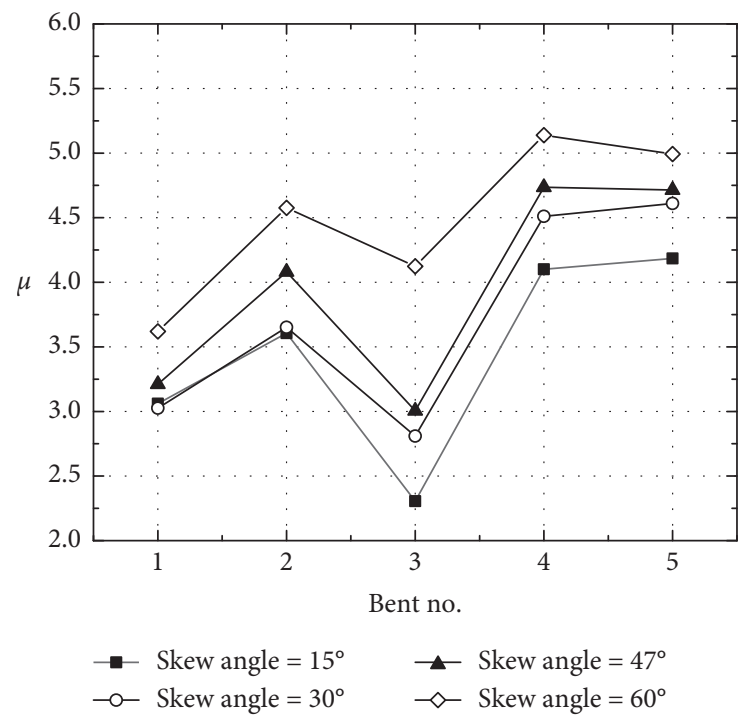

(b)

FIGURE 17: Displacement ductility demands of bridge models with different skew angles. (a) Longitudinal direction. (b) Transverse direction.

transverse direction, the ductility demands might increase with an increase in the skew angle.

5.3. Effect of Friction Coefficient. The sliding between the bearings and girders was significantly affected by the friction coefficient. Caltrans [29] specified a dynamic friction coefficient of 0.4 between concrete and neoprene, and 0.35 between neoprene and steel. The friction coefficient might depend on the sliding velocity and temperature. The sensitivity of the response was determined using two sets of friction coefficients. The coefficient between the laminated- rubber bearings and the girders $\left(C_{R}\right)$ was varied from 0.2 to 0.5 , while the coefficient between the PTFE sliding bearings and girders $\left(C_{T}\right)$ was kept constant at 0.02 for the first group. In the second group, $C_{R}$ was constant at 0.3 , but $C_{T}$ was varied from 0.005 to 0.02 .

The numerical results with different $C_{R}$ values are compared in Figures 18 and 19. As shown in Figure 18, the maximum and average values of the maximum displacements of all the bearings are not sensitive to $C_{R}$ values, except for the maximum values in the transverse direction, which increase with the increase of $C_{R}$ values. On the other hand, the residual displacements of the bearings are significantly affected by the variations 


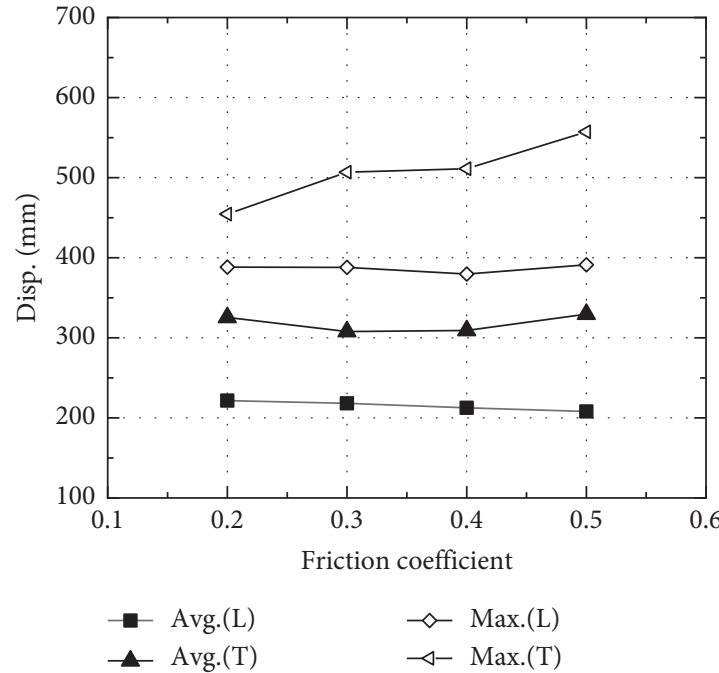

(a)

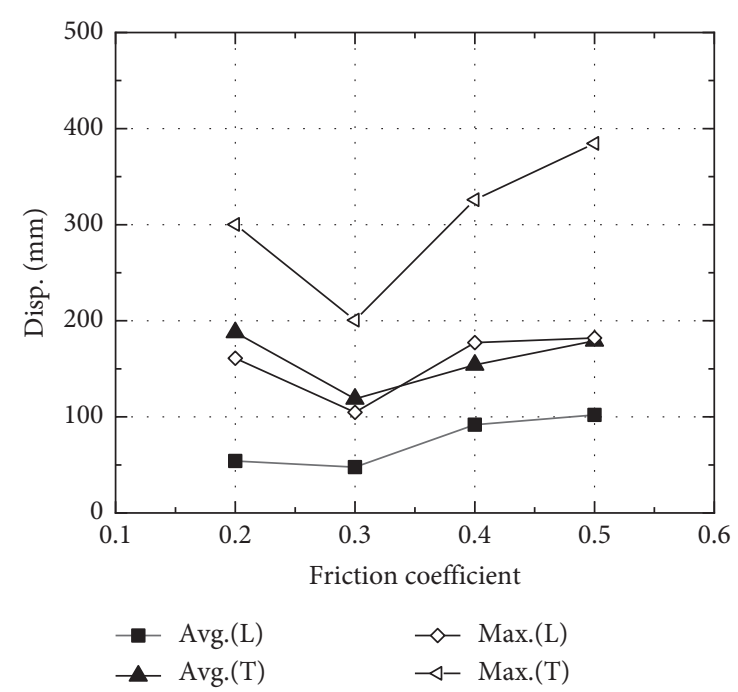

(b)

FIGURE 18: Effect of $C_{R}$ on the bearing displacements. (a) Maximum displacement. (b) Residual displacement.

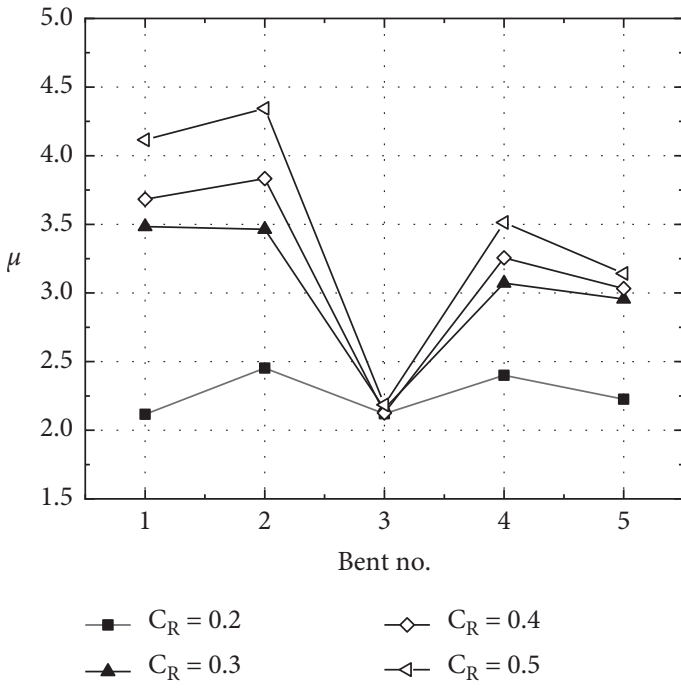

(a)

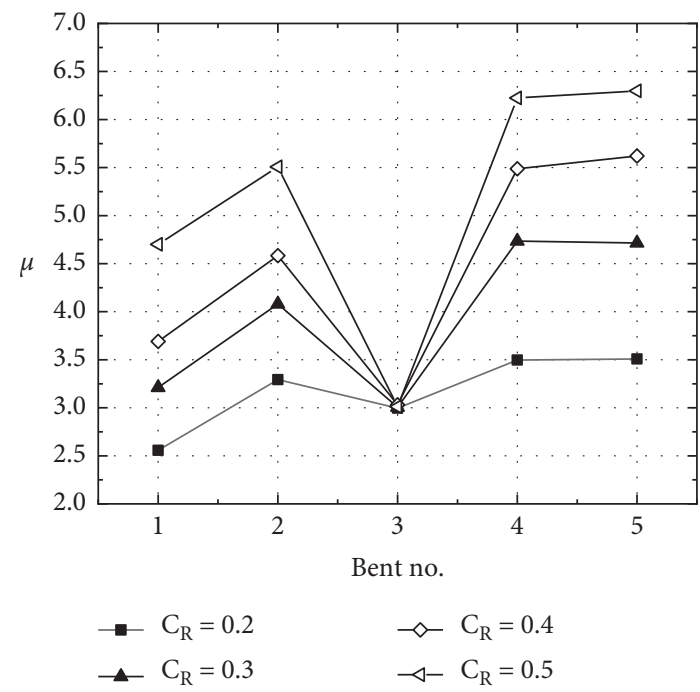

(b)

FIgURE 19: Effect of $C_{\mathrm{R}}$ on the displacement ductility demands. (a) Longitudinal direction. (b) Transverse direction.

of $C_{R}$ values. The influence of $C_{R}$ on the residual displacements (in Figure 18(b)) is erratic and no clear trends can be identified. When the $C_{R}$ is 0.3 , the average and maximum values of the residual displacements of all the bearings reach the minimum in the transverse and longitudinal directions.

In Figure 19, it can be seen that, except for bent 3, the longitudinal and transverse displacement ductility demands for the bents increased with an increase in $C_{R}$. This is because when the friction coefficient increased, the shear force transmitted from the bearings to the bents increased, resulting in larger displacement ductility demands. Because the bearings on bent 3 were PTFE sliding bearings with a constant friction coefficient of 0.02 , the response of bent 3 was not significantly affected by $C_{R}$.
The effect of $C_{T}$ on the seismic response is shown in Figures 20 and 21. The effect of $C_{T}$ on the seismic displacements of bearings was approximately the same as that of $C_{R}$. The residual displacements were more sensitive to $C_{T}$ compared to the maximum displacements. An increase in $C_{T}$ decreased the average and maximum values of the longitudinal residual displacements; however, it did not necessarily lead to a reduction in the transverse residual displacements.

As shown in Figure 21, the displacement ductility demands of the bents appeared to be insensitive to a variation in $C_{T}$. The possible reason is that $C_{T}$ was very small compared with $C_{R}$. Therefore, with a variation in $C_{T}$, the total force on the bents changed only by a small amount and 


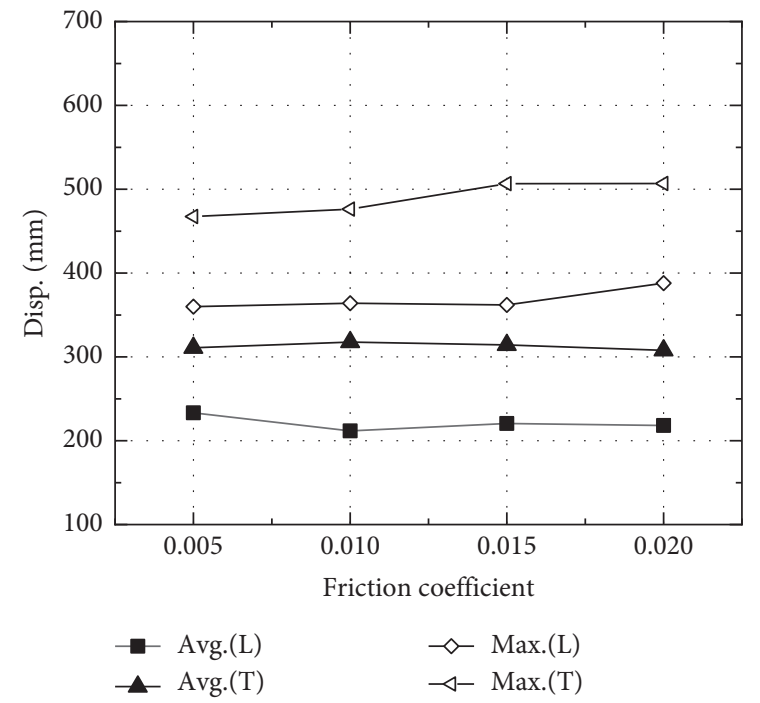

(a)

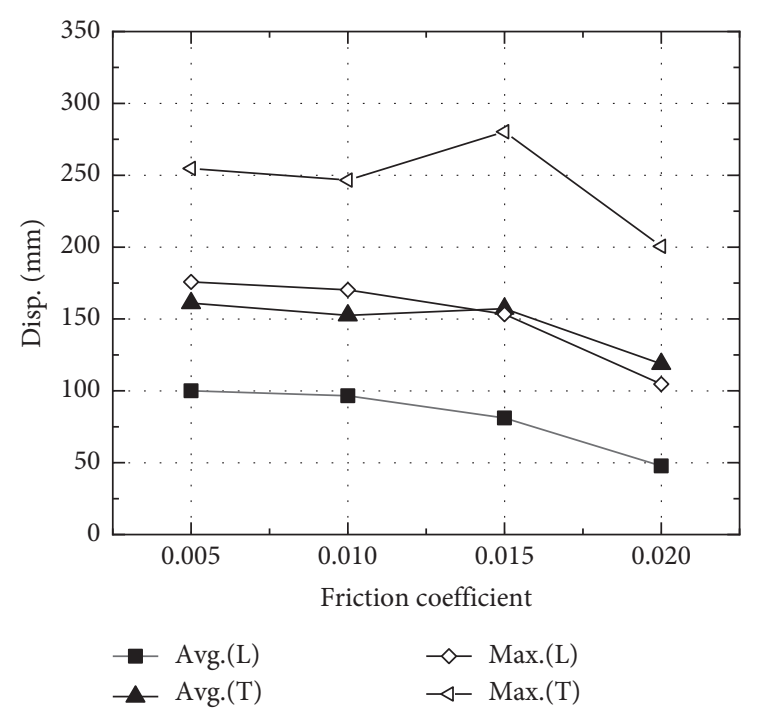

(b)

Figure 20: Effect of $C_{T}$ on the seismic displacements of bearings. (a) Maximum displacement. (b) Residual displacement.

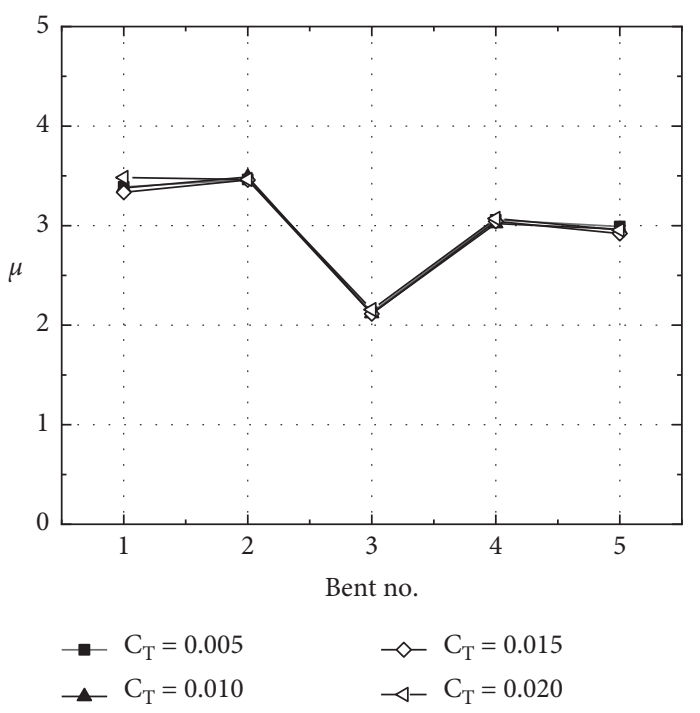

(a)

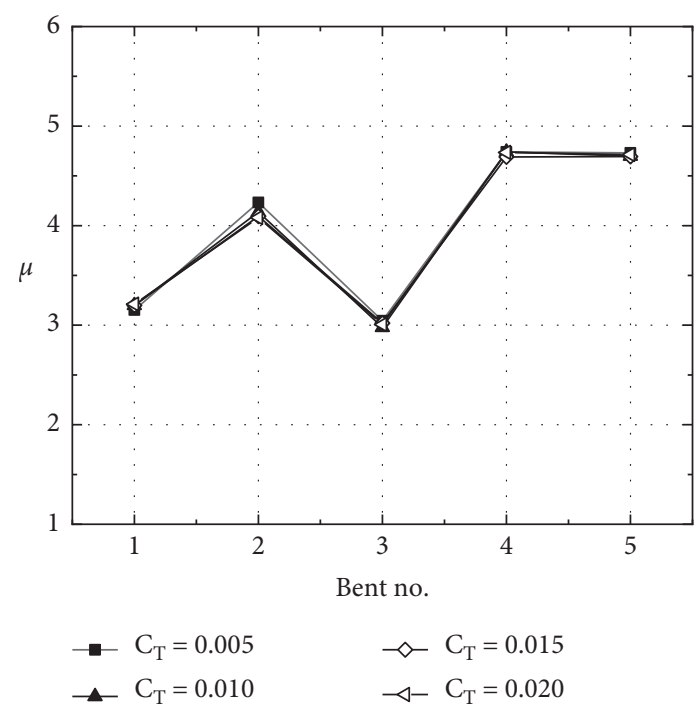

(b)

Figure 21: Effect of $C_{T}$ on the displacement ductility demands of bents. (a) Longitudinal direction. (b) Transverse direction.

hence, the displacement ductility demands of the bents were not significantly affected.

\section{Conclusions}

From this study, the following conclusions could be drawn:

(1) Large sliding displacements occurred between the laminated-rubber bearings and the girders for the Duxiufeng Bridge under the 2008 Wenchuan earthquake.

(2) Compared with the bridge with a pin-free bearing or rubber bearing, the displacement ductility demands of the bents were relatively large in the longitudinal and transverse directions for the skew bridge with a pin-roller bearing.

(3) The cable restrainers with an appropriate stiffness could effectively reduce the longitudinal residual displacements of the bearings.

(4) The effect of the skew angle was less significant for the bridge with the bearings than for a rigid-frame bridge because of the sliding between the girders and the laminated-rubber bearings.

(5) The residual displacements were more sensitive to the variation in the friction coefficient between the laminated-rubber bearings and the girders compared with the maximum seismic displacements. However, 
the displacement ductility demands of the bents increased with an increase in the friction coefficient. The friction coefficient between the PTFE sliding bearings and the girders had an insignificant impact on the seismic response of the bridge.

As the current study considered one specific type of skew bridges without considering the effect of geometric variations, such as bent height and span length, a further study using different skew bridges with various configurations should be conducted for a better understanding of the seismic response of such irregular bridges. This study investigated the seismic performance of a laminated-rubber bearing-supported skew bridge, considering bearing sliding only under horizontal earthquakes. In addition to the cable restrainers, the effectiveness of other possible restrainers, such as concrete shear keys and yielding steel dampers, should be studied for better seismic retrofitting of skew bridges.

\section{Data Availability}

All data and models generated or used during the study are available from the corresponding author upon request (data for figures and finite element models).

\section{Conflicts of Interest}

The authors declare that they have no conflicts of interest.

\section{Acknowledgments}

This study was financially supported by the Scientific and Technical Project on Western Transportation Construction (no. 2008318200098) for the project "Seismic Damage Evaluation, Mechanism Analysis and Evaluation of Seismic Fortification Criterion on Highway during Wenchuan Earthquake" and the Postdoctoral Science Fund Project of Chongqing Natural Science Foundation (no. cstc2020jcyjbshX0086). The supports are gratefully acknowledged.

\section{References}

[1] F. Seible and M. J. N. Priestley, "Lessons learned from bridge performance during Northridge earthquake," Special Publication, vol. 187, pp. 29-56, 1999.

[2] S. Hashimoto, Y. Fujino, and M. Abe, "Damage analysis of Hanshin Expressway viaducts during 1995 Kobe earthquake. II: damage mode of single reinforced concrete piers," Journal of Bridge Engineering, vol. 10, no. 1, pp. 54-60, 2005.

[3] Y. T. Hsu and C. C. Fu, "Seismic effect on highway bridges in Chi Chi earthquake," Journal of Performance of Constructed Facilities, vol. 18, no. 1, pp. 47-53, 2004.

[4] Q. Han, X. Du, J. Liu, Z. Li, L. Li, and J. Zhao, "Seismic damage of highway bridges during the 2008 Wenchuan earthquake," Earthquake Engineering and Engineering Vibration, vol. 8, no. 2, pp. 263-273, 2009.

[5] N. Xiang and J. Li, "Seismic performance of highway bridges with different transverse unseating-prevention devices," Journal of Bridge Engineering, vol. 21, no. 9, Article ID 04016045, 2016.
[6] J. Li, N. Xiang, H. Tang, and Z. Guan, "Shake-table tests and numerical simulation of an innovative isolation system for highway bridges," Soil Dynamics and Earthquake Engineering, vol. 86, pp. 55-70, 2016.

[7] J. Li, T. Peng, and Y. Xu, "Damage investigation of girder bridges under the Wenchuan earthquake and corresponding seismic design recommendations," Earthquake Engineering and Engineering Vibration, vol. 7, no. 4, pp. 337-344, 2008.

[8] D. Konstantinidis, J. M. Kelly, and N. Makris, "Experimental investigation on the seismic response of bridge bearings," Earthquake Engineering Research Center; University of California, Berkeley, CA, USA, UCB/EERC-2008/02, 2008.

[9] J. S. Steelman, L. A. Fahnestock, E. T. Filipov et al., "Shear and friction response of nonseismic laminated elastomeric bridge bearings subject to seismic demands," Journal of Bridge Engineering, vol. 18, no. 7, pp. 612-623, 2012.

[10] N. Xiang and J. Li, "Experimental and numerical study on seismic sliding mechanism of laminated-rubber bearings," Engineering Structures, vol. 141, pp. 159-174, 2017.

[11] N. Xiang, M. S. Alam, and J. Li, "Shake table studies of a highway bridge model by allowing the sliding of laminatedrubber bearings with and without restraining devices," Engineering Structures, vol. 171, pp. 583-601, 2018.

[12] N. Xiang, M. S. Alam, and J. Li, "Yielding steel dampers as restraining devices to control seismic sliding of laminated rubber bearings for highway bridges: analytical and experimental study," Journal of Bridge Engineering, vol. 24, no. 11, Article ID 04019103, 2019.

[13] M. Saiidi, M. Randall, E. Maragakis, and T. Isakovic, "Seismic restrainer design methods for simply supported bridges," Journal of Bridge Engineering, vol. 6, no. 5, pp. 307-315, 2001.

[14] J.-H. Won, H.-S. Mha, K.-I. Cho, and S.-H. Kim, "Effects of the restrainer upon bridge motions under seismic excitations," Engineering Structures, vol. 30, no. 12, pp. 3532-3544, 2008.

[15] J.-q. Wang, S. Li, F. Hedayati Dezfuli, and M. S. Alam, "Sensitivity analysis and multi-criteria optimization of SMA cable restrainers for longitudinal seismic protection of isolated simply supported highway bridges," Engineering Structures, vol. 189, pp. 509-522, 2019.

[16] S. Li, F. H. Dezfuli, J.-q. Wang, and M. S. Alam, "Longitudinal seismic response control of long-span cable-stayed bridges using shape memory alloy wire-based lead rubber bearings under near-fault records," Journal of Intelligent Material Systems and Structures, vol. 29, no. 5, pp. 703-728, 2018.

[17] A. A. Ghobarah and W. K. Tso, "Seismic analysis of skewed highway bridges with intermediate supports," Earthquake Engineering \& Structural Dynamics, vol. 2, no. 3, pp. 235-248, 1973.

[18] R. S. Srinivasan and K. Munaswamy, "Dynamic response of skew bridge decks," Earthquake Engineering \& Structural Dynamics, vol. 6, no. 2, pp. 139-156, 1978.

[19] E. A. Maragakis and P. C. Jennings, "Analytical models for the rigid body motions of skew bridges," Earthquake Engineering \& Structural Dynamics, vol. 15, no. 8, pp. 923-944, 1987.

[20] J. Y. Meng and E. M. Lui, "Seismic analysis and assessment of a skew highway bridge," Engineering Structures, vol. 22, no. 11, pp. 1433-1452, 2000.

[21] J. Chen, Q. Han, X. Liang, and X. Du, "Effect of pounding on nonlinear seismic response of skewed highway bridges," Soil Dynamics and Earthquake Engineering, vol. 103, pp. 151-165, 2017.

[22] A. Abdel-Mohti and G. Pekcan, "Effect of skew angle on seismic vulnerability of RC box-girder highway bridges," 
International Journal of Structural Stability and Dynamics, vol. 13, no. 6, Article ID 1350013, 2013.

[23] S. P. Deepu, K. Prajapat, and S. Ray-Chaudhuri, "Seismic vulnerability of skew bridges under bi-directional ground motions," Engineering Structures, vol. 71, pp. 150-160, 2014.

[24] S. Wu, I. G. Buckle, A. M. Itani et al., "Experimental studies on seismic response of skew bridges with seat-type abutments. I: shake table experiments," Journal of Bridge Engineering, vol. 24, no. 10, Article ID 04019096, 2019.

[25] S. Wu, I. G. Buckle, A. M. Itani et al., "Experimental studies on seismic response of skew bridges with seat-type Abutments. II: results," Journal of Bridge Engineering, vol. 24, no. 10, Article ID 04019097, 2019.

[26] S. Wu, "Unseating mechanism of a skew bridge with seat-type abutments and a Simplified Method for estimating its support length requirement," Engineering Structures, vol. 191, pp. 194-205, 2019.

[27] S. M. Rasouli and M. Mahmoodi, "Assessment the effect of skewness and number of spans in seismic behavior of bridges with continuous multiple spans using MPA," KSCE Journal of Civil Engineering, vol. 22, no. 4, pp. 1328-1335, 2018.

[28] Ministry of Transport of the People's Republic of China, "Guidelines for seismic design of highway bridges," Ministry of Transport of the People's Republic of China, Beijing, China, JTG/T B02-01-2008, 2008.

[29] E. L. Wilson, Three Dimensional Static and Dynamic Analysis of Structures, Computers and Structures, Berkeley, CA, USA, 2000.

[30] J. B. Mander, M. J. N. Priestley, and R. Park, "Theoretical stress-strain model for confined concrete," Journal of Structural Engineering, vol. 114, no. 8, pp. 1804-1826, 1988.

[31] Ministry of Transport of the People's Republic of China, "Code for Design of Highway Reinforced Concrete and Prestressed Concrete Bridges and Culverts," Ministry of Transport of the People's Republic of China, Beijing, China, JTG D62-2004, 2004.

[32] X. Huang and J. Li, Experimental and Analytical Study on Unseating Prevention System for Continuous Bridge, Tongji University, Shanghai, China, 2009, In Chinese.

[33] S. D. C. Caltrans, Caltrans Seismic Design Criteria Version 1.6, California Department of Transportation, Sacramento, CA, USA, 2010. 